\title{
Performance Evaluation of Computer Simulated Extracted Features of Induction Motor with Intermediate State of Degradation Present in Any-One Phase
}

\author{
Amit J. Modak \\ Ph. D. Research Student \\ Electrical Engineering \\ Walchand College of Engineering, Sangli, India
}

\author{
Dr. H.P. Inamdar \\ Research Professor \\ Electrical Engineering \\ Rajarambapu Institute of Technology, \\ Rajaramnagar, District-Sangli, India
}

\begin{abstract}
The state of degradation of stator groundwall insulation in induction motor results in the state of unbalance in threephase stator current at fundamental frequency. In this investigation, the computer simulation model to determine this state of unbalance is developed. On the basis of park's transformation model the unbalanced stator current data in three-phase machine variable ('abc') form is transformed into equivalent two-phase ('dq') model form. The park's current vector components are then presented in a graphical dq-data pattern form and certain mathematical parameters are deduced. The computer simulation model is designed to extract simulated electrical variables and mathematical parameters of induction motor under test. The practical assumption of stator winding of induction motor being star (Y) connected with isolated neutral is considered. The extracted features of induction motor for particular case of variation in the state of degradation of stator groundwall insulation occurring in respective phases is presented. The performance evaluation of extracted features for the variation in the state of degradation of insulation in any two-phases with an intermediate state of degradation present in the remaining phase is presented. On the basis of performance evaluation, it is possible to determine the appropriate selection of specific input parameter for optimal design of suitable artificial neural network classifier to distinguish the probable states of degradation of insulation.
\end{abstract}

\section{General Terms}

Modeling and Simulation, Diagnostic and Decision Supporting System

\section{Keywords}

Computer simulation, insulation degradation, induction motor, park's current transformation, stator groundwall insulation.

\section{INTRODUCTION}

The stator insulation system of a typical three phase induction motor consists of strand and turn insulation, as well as groundwall insulation. The groundwall is the primary insulation, separating the high voltage copper conductors from the grounded steel core. Modem machines use mica flake or mica paper tapes bonded with epoxy or polyester resin as the groundwall insulation. In addition to these components, the insulation system of a bar or coil also includes a semi conductive coating over the slot-section groundwall, with a special coating at the ends of the slots to grade the electric stress in this region. These insulation failures are usually the result of gradual deterioration of the insulation due to aging. The aging results from electrical, mechanical and thermal stresses. The diagnostic tests and measurements to assess the condition of stator winding insulation in a particular machine are mainly classified in two broad categories viz., destructive tests and nondestructive tests. Both the type of test measures are as such relatively insensitive life indicators of stator winding insulation, which still have significant remaining life $[1,2]$.

More or less the credibility in estimating the insulation condition under nondestructive tests must be correlated with the results of destructive tests [3]. In the previous investigations it is ascertained that there is no correlation between the results of any non destructive type of (dc / ac) assessment parameters with destructive type of (dc / ac / impulse) breakdown levels [4]. There is a need to establish an economical nondestructive test method for an assessment of state of degradation of stator groundwall insulation caused due to various factors in an integrated way. This is particularly true in case of large numbers of low / medium capacity three phase induction motors operating in variable speed drive environment in any continuous process industry.

\section{FORMULATION OF WORK WITH THEORETICAL JUSTIFICATION}

In view of the above perspective, the present research work presents a novice nondestructive method to assess the state of degradation of stator winding insulation. The method is based on the concept that the degradation occurring in any one of the phases of stator winding insulation, effectively results in the state of unbalance in the three-phase stator current at fundamental supply frequency. The state of degradation of insulation, occurring on account of several reasons, in an integrated way can be readily represented in terms of magnitude and degree of unbalance in the stator current at fundamental supply frequency. The emphasis is towards the application of such unbalanced stator current numerical data to a suitable artificial intelligence (AI) based tool to determine the state of degradation of stator insulation. On experimental basis it is not feasible to collect the large set of unbalanced stator current data, which would model the entire range of state of degradation of insulation for the specific motor used in particular industry. However, in neural network based AItechnique, a large set of data pattern availability is required for the development of diagnostic model to detect the state of 
degradation of stator groundwall insulation. This is essential from the point of view of optimal design and efficient performance of the neural network classifier. Hence, there is need to generate large number of unbalanced stator current numerical data on the basis of computer simulation model to represent the various states of degradation of stator groundwall insulation occurring in respective phases. The formulation and execution of computer simulation model to generate unbalanced stator current data pattern was done in the previous work [5]. In the previous work, the modeling was based on the assumption that the stator winding was starconnected with grounded neutral. As against this, in the present investigation, based on the similar approach, the formulation of computer simulation model is derived based on the practical condition of isolated neutral. The modeling is done for three-phase, cage-rotor, 10-HP, and star (Y)connected ac induction motor used in a continuous process industry.

In general, the motor is operating under the presence of many internal and external recipient faults. In the spectrum analysis based fault diagnosis techniques [6,7], it is concluded that these faults are observable at some definite frequencies, which are different than the supply frequency. These stator winding faults are present due to several causes like high level of stator circuit asymmetry, air gap flux intensity variations [8], broken stator/rotor bars, cage rotor faults [9], inter-turn short circuit insulation failure [10], air gap eccentricity [11] etc; but not on account of degradation of stator groundwall insulation. The state of degradation of stator groundwall insulation of the respective phase results into the reduction of resistance to the thermal conductivity. This results into an increase in the rate of heat transfer from the surface of the stator winding conductors to the remaining part of the structure. This excessive heat loss to the surroundings is interpreted as the motor is subjected to excessive copper losses bearing the loss in efficiency at the supply frequency. Hence, motor draws more current as compared to what it would have drawn had the insulation not degraded. In view of the above reasons, the increase in current in respective phases leads to an unbalance in stator current at fundamental supply frequency.

The increase in current is accompanied as reduction in the steady-state equivalent resistance of motor referred to stator. The state of degradation of insulation of the respective phase, also results in the increase in the leakage current. This is on account of decrease in the magnetizing reactance component (i.e., " $\mathrm{X}_{\mathrm{m}}$ "). The combined effect of the above two factors is interpreted as the reduction in the real part of the equivalent impedance of the motor referred to stator under the absence of mechanical load condition. The imaginary part of the equivalent impedance of the motor referred to stator under the absence of mechanical load condition will not change much since the inductance does not contribute to the dissipation of any energy on account of loss of heat to the surroundings. In the present work, as shown in the Fig. 1 below, the reduction in the real part of an equivalent impedance of motor referred to stator under the absence of mechanical load condition (i.e., "Real (Zseq1_im_nl)") is simulated by the presence of suitable values of variable shunt resistance (i.e., " $\mathrm{R}_{\mathrm{sh}}$ ") connected across it in the lumped form.

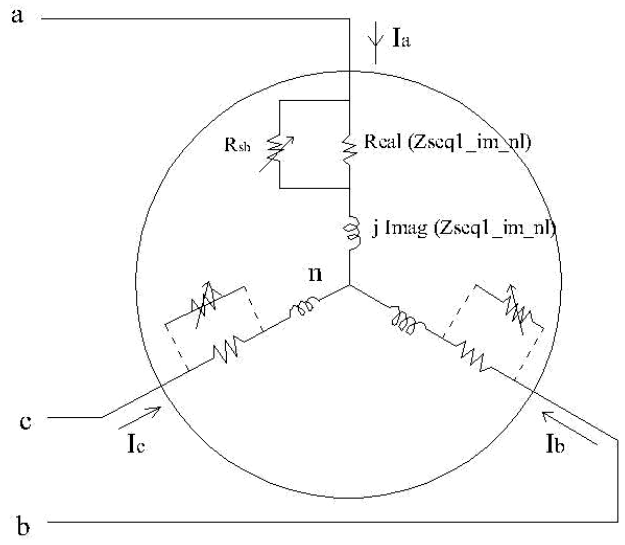

Fig 1: Simulation of State of Degradation of Stator Groundwall Insulation of Respective Phase with Isolated Neutral

The computer simulation program is designed to generate unbalanced three-phase stator current data pattern on the basis of the resultant steady-state equivalent motor impedance perphase. The resultant stator current data pattern is simulating the specific state of degradation of stator groundwall insulation of the respective phases of the motor under test. The computer simulation program incorporates the feature of extended park's transformation model to transform the threephase unbalanced stator current data patterns in the threephase ('abc') machine variable form into two-phase ('dq') park's current vector component form. The graphical representations of resultant park's current 'dq' data pattern forms are illustrated. The computer simulation model is designed further to execute the extraction of various electrical variables and mathematical parameters, which specifically distinguish the state of degradation of stator groundwall insulation of respective phases. The detailed analysis and the summary of the series of extracted variables and mathematical parameters are presented for the particular case of the state of degradation of stator groundwall insulation.

\section{COMPUTER SIMULATION MODEL FOR EVALUATION OF STATE OF DEGRADATION OF STATOR GROUNDWALL INSULATION}

The simulation model is designed on the basis of certain assumptions and reference conditions in context to the representation of balanced line voltages and the resulting unbalanced phase voltages and stator currents, over a phase plane.

\subsection{Nomenclature}

The nomenclature of various variables involved in the simulation model is detailed as under. The representation of the electrical variables over a phase plane is as shown in Fig. 2. The bold face symbolic representation of respective variables represents their corresponding RMS values.

$\mathrm{V}_{\mathrm{ab}}, \mathrm{V}_{\mathrm{bc}}, \mathrm{V}_{\mathrm{ca}}$ The absolute values of three-phase, balanced, line-to-line supply voltages across the respective phases (viz., 'a, b, 
and c' of star-(Y) connected stator winding with isolated neutral, respectively.), in 'Volts.'

$\mathrm{V}_{\mathrm{a}}, \mathrm{V}_{\mathrm{b}}, \mathrm{V}_{\mathrm{c}}$

$\alpha_{\mathrm{a}}, \alpha_{\mathrm{b}}, \alpha_{\mathrm{c}}$

$\mathrm{I}_{\mathrm{a}}, \mathrm{I}_{\mathrm{b}}, \mathrm{I}_{\mathrm{c}}$

$\beta_{\mathrm{a}}, \beta_{\mathrm{b}}, \beta_{\mathrm{c}}$

$\mathrm{Z}_{\mathrm{a}}, \mathrm{Z}_{\mathrm{b}}, \mathrm{Z}_{\mathrm{c}}$

$\mathrm{Z}_{0}$

$\mathrm{I}_{\mathrm{d}}, \mathrm{I}_{\mathrm{q}}, \mathrm{I}_{0}$

$\beta_{\mathrm{d}}, \beta_{\mathrm{q}}$

$\mathrm{I}_{\mathrm{dq}}$

$\beta_{\mathrm{dq}} \quad$ The phase angle of resultant of 'directaxis' and 'quadrature-axis' current component per-phase of the equivalent ' 2 phase' machine ('dqo') model, expressed in electrical degrees (' $\left.{ }^{\circ}\right)$.

$\mathrm{L}_{\mathrm{MA}}, \mathrm{L}_{\mathrm{MB}}$, $\mathrm{LR}$ The length of major axis (' $\mathrm{L}_{\mathrm{MA}}$ '), length of minor axis (' $\mathrm{L}_{\mathrm{MB}}$ '), and latus rectum ('LR') of extended park's current data pattern, in ('Amps.'). $\theta_{0}{ }^{\circ}$ across the phases (viz., ' $a, b$, and c' of star-(Y) connected stator winding with respect to isolated neutral, respectively.), in 'Volts.' across the phases (viz., ' $a, b$, and c,' respectively.), expressed in electrical degrees ( ${ }^{\circ}$ ') phase of the phases (viz., 'a, b, and c,' respectively.), in 'Amps.' phases (viz ' $a$, b, and c', respectively.) expressed in electrical degrees ( $\left.{ }^{\circ} \circ\right)$.

The absolute values of steady-state equivalent motor impedances per-phase refered to stator for the operation of motor under the absence of mechanical load condition corresponding to some finite values of shunt resistances (' $R_{\mathrm{sh}}$ ') between maximum (viz., close to infinity$\infty$ ) and minimum value (viz., close to zero- 0 ), in ohms (' $\Omega$ ').

The absolute value of steady-state equivalent motor impedance per-phase refered to stator for the operation of motor under the absence of mechanical load condition, for the value of shunt resistance (' $R_{\text {sh }}$ ') equal to infinity $(\infty)$, in ohms (' $\Omega$ ').

The absolute values of direct-axis, quadrature-axis, and zero-sequence current per-phase of the equivalent '2respectively, in ('Amps.'). (2) model, respectively, in electrical degrees ('0'). component per-phase of the equivalent ' 2 phase' machine ('dqo') model, in ('Amps').
Eccentricity (' $\varepsilon$ ') of extended park's current data pattern.

$\theta_{0} \quad$ Orientation angle of extended park's current data pattern (locus), measured with respect to reference with anticlockwise sense as positive, expressed in electrical degrees (' ${ }^{\circ}$ ).

$\theta_{\mathrm{m}}{ }^{\circ} \quad$ Angle of major axis of extended park's current data pattern, measured with respect to reference axis with anticlockwise sense as positive, in electrical degrees ('0').

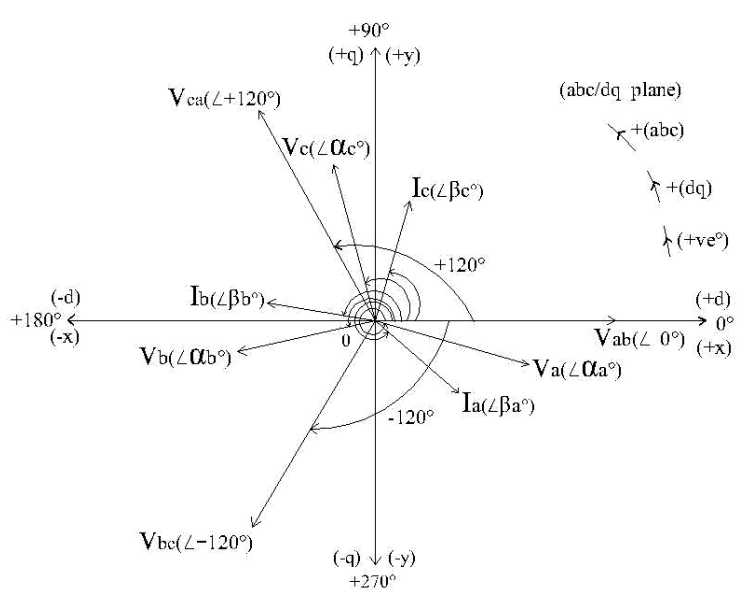

Fig 2: Phase Plane Representation of Electrical Variables

\subsection{Determination of Steady State Unbalanced Stator Currents Per-Phase}

The computer simulation of steady-state equivalent circuit of induction motor with rotor at stator frequency is done on 'MATLAB.' The measured machine parameters are used to assess the performance of cage-rotor induction motor in the machine variable form under minimum mechanical load condition. The minimum mechanical load condition is realized under the absence of mechanical load, by decoupling the mechanical load from the shaft of motor. Simulation analysis is conducted on three-phase, $10 \mathrm{HP}(7.5-\mathrm{kW})$, sixpole, and star $(\mathrm{Y})$ connected induction motor. The steps involved in the development of simulation model for the evaluation of state of degradation of insulation are as under-

a) Determination of machine parameters for induction motor under test.

b) The computation of steady state performance of induction motor in machine variable form under minimum mechanical load condition.

c) Evaluation of maximum and minimum values of shunt resistances across the real part of equivalent steady state motor impedance per-phase referred to stator side at stator frequency under minimum mechanical load condition.

d) The computation of the numerical values of number of shunt resistances between maximum and minimum values, which are simulating different state of degradation of stator groundwall insulation. 
e) The numbers of steady-state equivalent motor impedances per-phase refered to stator side (i.e., Zseq1_im_nl_xd) under the absence of mechanical load condition are computed for the range of values of shunt resistances (i.e., $\mathrm{R}_{\mathrm{sh}}$ ) within maximum and minimum values. The simulation results for the same computations are presented in 'Table 1.'

As shown in the 'Table 1,' the absolute value of steady-state motor impedance per-phase corresponding to an infinte $(\infty)$ value of shunt resistance $\left(\mathrm{R}_{\text {sh }}\right)$, represents the healthy state of stator groundwall insulation of the respective phase. Similarly, the absolute value corresponding to some finite minimum value of shunt resistance (viz., $1.6847 \Omega$ ) represents a finite worst-case state of degradation of stator groundwall insulation of the respective phase. The absolute value corresponding to the value of shunt resistance anything in between finite maximum and minimum value represents an arbitrary intermediate state of degradation of the respective phase. The numbers of combinations of these numerical values of steady state equivalent motor impedances per-phase refered to stator are determined to model the numbers of various states of degradation.

Table 1. Simulation results of steady-state motor impedances per-phase.

\begin{tabular}{|c|c|c|}
\hline $\begin{array}{l}\mathbf{R}_{\text {sh }} \\
(\boldsymbol{\Omega})\end{array}$ & $\begin{array}{c}\text { Percentage of } \\
\text { Reduction in Real } \\
\text { Part of (Zseq1_im_nl) } \\
(\%)\end{array}$ & $\begin{array}{c}\text { Absolute Value of } \\
\text { Zseq1_im_nl_xd } \\
(\Omega)\end{array}$ \\
\hline$\infty$ & 0 & 36.7698 \\
\hline 608.1699 & 5 & 35.3853 \\
\hline 288.0805 & 10 & 34.0198 \\
\hline 96.0268 & 25 & 30.0627 \\
\hline 48.0134 & 40 & 26.3873 \\
\hline 32.0089 & 50 & 24.1575 \\
\hline 21.3393 & 60 & 22.167 \\
\hline 10.6696 & 75 & 19.7858 \\
\hline 3.5565 & 90 & 18.3763 \\
\hline 1.6847 & 95 & 18.166 \\
\hline
\end{tabular}

The overall percentage of degradation (i.e., "per_xd (\%)") is represented in numerical form by the concept of root mean square value of absolute deviation of impedances (i.e., " $Z$ _ $x d$ $(\Omega)$ "), in three phases. The same is now proposed with the following analytical definition.

$Z_{-} x d=\left(\sqrt{\left(\left(Z_{0}-Z_{a}\right)^{2}+\left(Z_{0}-Z_{b}\right)^{2}+\left(Z_{0}-Z_{c}\right)^{2}\right)}\right) \times$

$$
\text { per_xd }(\%)=\left(\left(Z_{-} x d\right) /\left(Z_{0}\right)\right) \times 100
$$

The simple subroutine program is designed to determine numbers of such possible combinations for respective phases. These numbers of combinations of steady state motor impedances per-phase are used further to compute the stator currents per-phase. The resulting unbalanced stator currents per-phase are computed under the condition of balanced supply voltage of star $(\mathrm{Y})$ connected stator winding with isolated neutral i.e., (2) and (3).

$$
\begin{aligned}
& \boldsymbol{V}_{a b}+\boldsymbol{V}_{b c}+V_{c a}=0 \\
& \boldsymbol{I}_{a}+\boldsymbol{I}_{b}+\boldsymbol{I}_{c}=0
\end{aligned}
$$

The equations for the corresponding stator currents for the respective phases based on condition (2) and (3) are derived as under-

$$
\begin{aligned}
& I_{a}=\left(\left(Z_{b}+Z_{c}\right) V_{a b}+Z_{b} V_{b c}\right) /\left(Z_{a} Z_{b}+Z_{b} Z_{c}+Z_{c} Z_{a}\right) \\
& I_{b}=\left(-Z_{c} V_{a b}+Z_{a} V_{b c}\right) /\left(Z_{a} Z_{b}+Z_{b} Z_{c}+Z_{c} Z_{a}\right) \\
& I_{c}=-\left(Z_{b} V_{a b}+\left(Z_{a}+Z_{b}\right) V_{b c}\right) /\left(Z_{a} Z_{b}+Z_{b} Z_{c}+Z_{c} Z_{a}\right)
\end{aligned}
$$

The computer simulation program is designed to generate around ' $\mathrm{m}=8000$ ' number of unique combinations of unbalanced three-phase stator current data pattern. Each one of these data pattern is simulating the specific state of degradation of stator groundwall insulation of the respective phases of the motor under test. The simulation results of motor variables like- overall percentage of degradation of insulation (i.e., "per_xd (\%)") in the form of matrix (i.e., "[per_xd] $]_{\mathrm{mx}}$ "), absolute value of steady-state motorimpedances per-phase for respective phases in the form of matrix (i.e., "[ $\left[\begin{array}{lll}Z_{a} & Z_{b} & Z_{c}\end{array}\right]_{m \times 3}$ ") in $\Omega$, absolute values and phase-shift angles of stator current per-phase for respective phases in the form of matrix (i.e., "[ $\left.\begin{array}{llllll}I_{a} & I_{b} & I_{c} & \beta_{a} & \beta_{b} & \beta_{c}\end{array}\right]_{m \times 6}$ ") in amperes and electrical degrees, respectively, are detailed in 'Table 2.' The 'Table 2' represents the simulation data for few numbers (No.) of unique combinations of unbalanced threephase stator current data for a particular case of intermediate state of degradation of insulation present in any one particular phase with an equal variation in the state of degradation in other two-phases.

Table 2. Simulation results of electrical variables in three-phase machine model ('abc') form for intermediate state of degradation of insulation present in 'phase-a' with equal variation in state of degradation of insulation in 'phase-b' and 'phase-c'

\begin{tabular}{|c|c|c|c|c|c|c|c|c|c|c|}
\hline No. & $\begin{array}{c}\text { per_xd } \\
(\%)\end{array}$ & $\mathrm{Z}_{\mathrm{a}}(\Omega)$ & $\mathrm{Z}_{\mathrm{b}}(\Omega)$ & $\mathrm{Z}_{\mathrm{c}}(\Omega)$ & $\mathrm{I}_{\mathrm{a}}(\mathrm{A})$ & $\beta_{\mathrm{a}}\left(^{\circ}\right)$ & $\mathrm{I}_{\mathrm{b}}(\mathrm{A})$ & $\beta_{\mathrm{b}}\left({ }^{\circ}\right)$ & $\mathrm{I}_{\mathrm{c}}(\mathrm{A})$ & $\beta_{\mathrm{c}}\left({ }^{\circ}\right)$ \\
\hline 1 & 0.00 & 36.7698 & 36.7698 & 36.7698 & 6.5162 & 300.519 & 6.5162 & 180.519 & 6.5162 & 60.5195 \\
\hline 4001 & 19.8034 & 24.1575 & 36.7698 & 36.7698 & 8.5637 & 289.702 & 6.4117 & 169.528 & 7.6974 & 63.6391 \\
\hline 4106 & 24.7789 & 24.1575 & 30.0627 & 30.0627 & 9.2148 & 285.898 & 7.8112 & 167.165 & 8.7592 & 54.4575 \\
\hline 4169 & 30.3925 & 24.1575 & 26.3873 & 26.3873 & 9.6313 & 283.332 & 8.9762 & 164.322 & 9.4595 & 47.2484 \\
\hline 4211 & 34.3005 & 24.1575 & 24.1575 & 24.1575 & 9.9182 & 281.491 & 9.9182 & 161.491 & 9.9182 & 41.4911 \\
\hline 4253 & 37.9954 & 24.1575 & 22.167 & 22.167 & 10.2113 & 279.539 & 10.9903 & 157.683 & 10.3245 & 34.8297 \\
\hline 4316 & 42.5971 & 24.1575 & 19.7858 & 19.7858 & 10.6587 & 276.391 & 12.7533 & 149.782 & 10.6829 & 22.9982 \\
\hline 4400 & 45.8122 & 24.1575 & 18.166 & 18.166 & 11.258 & 271.762 & 14.8308 & 135.235 & 10.2158 & 4.5412 \\
\hline
\end{tabular}




\subsection{Extended Park's Current}

\section{Transformation Model for Computation of Direct-axis and Quadrature-axis Current} Components

The park's current vector pattern learning approach has been successfully applied in the fault diagnosis of ac induction motor drive $[11,12]$. In this investigation, the same approach is applied for the presentation of various states of degradation of insulation, occurring in respective phases of stator winding of induction motor. As shown in Fig. 3, the park's transformation model, transforms the presentation of unbalanced stator current data pattern in three-phase ('abc') machine variable form into two-phase ('dq') machine variable form over a phase-plane.

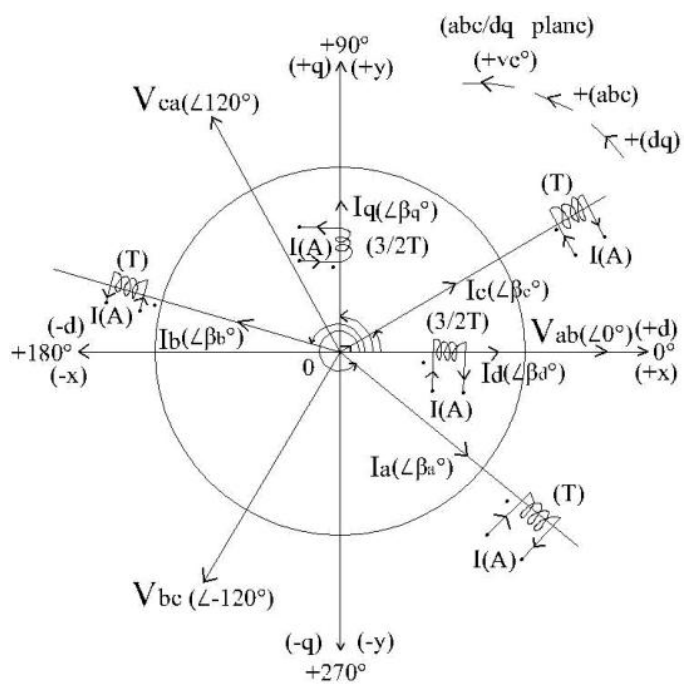

Fig 3: Extended Park's Current Transformation Model

For uniqueness of the transformation from one set of axes to another set of axes, including the unbalances in the 'abc' variables requires three variables such as 'dq0.' The relationship between ' $\mathrm{dq} 0$ ' and 'abc' current variables is derived as follows-

$$
\left[\begin{array}{c}
\boldsymbol{I}_{\boldsymbol{d}} \\
\boldsymbol{I}_{\boldsymbol{q}} \\
\boldsymbol{I}_{0}
\end{array}\right]=\frac{2}{3}\left[\begin{array}{ccc}
\cos \left(\beta_{a}^{\mathrm{o}}\right) & \cos \left(\beta_{b}^{\mathrm{o}}\right) & \cos \left(\beta_{c}^{\mathrm{o}}\right) \\
\cos \left(\beta_{a}^{\mathrm{o}}-90^{\circ}\right) & \cos \left(\beta_{b}^{\mathrm{o}}-90^{\circ}\right) & \cos \left(\beta_{c}^{\mathrm{o}}-90^{\circ}\right) \\
1 / 2 & 1 / 2 & 1 / 2
\end{array}\right]\left[\begin{array}{l}
\boldsymbol{I}_{a} \\
\boldsymbol{I}_{b} \\
\boldsymbol{I}_{c}
\end{array}\right]
$$

The zero sequence current ' $\mathbf{I}_{\mathbf{0}}$ ' (A) represents the imbalance in the 'phase-a, phase-b, and phase-c' currents. Under the practical condition of star $(\mathrm{Y})$ connected stator winding with isolated neutral, the zero sequence current component is always equal to zero and does not produce the resultant magnetic field. The relationship between ' $\mathrm{dq0}$ ' and ' $\mathrm{abc}$ ' currents is modified as follows-

$$
\left[\begin{array}{c}
\boldsymbol{I}_{d} \\
\boldsymbol{I}_{q}
\end{array}\right]=\frac{2}{3}\left[\begin{array}{ccc}
\cos \left(\beta_{a}^{\circ}\right) & \cos \left(\beta_{b}^{\circ}\right) & \cos \left(\beta_{c}^{\circ}\right) \\
\cos \left(\beta_{a}^{\mathrm{o}}-90^{\circ}\right) & \cos \left(\beta_{b}^{\mathrm{o}}-90^{\circ}\right) & \cos \left(\beta_{c}^{\circ}-90^{\circ}\right)
\end{array}\right]\left[\begin{array}{l}
\boldsymbol{I}_{a} \\
\boldsymbol{I}_{b} \\
\boldsymbol{I}_{c}
\end{array}\right]
$$

The extended park's current transformation model detailed in (8) is included in computer simulation program to compute park's current data pattern for all possible combinations of unbalanced three-phase stator currents. The simulation results of extended park's current data pattern for particular case of intermediate state of degradation of insulation present in any one-phase with an equal variation in the state of degradation in other two-phases of induction motor under test are listed in 'Table 3.' The graphical representations of extended park's current data pattern are in an elliptic form. The computer program is designed further to extract certain mathematical parameters like length of major axis $\left(\mathrm{L}_{\mathrm{MA}}\right)$, length of minor axis $\left(\mathrm{L}_{\mathrm{MB}}\right)$, eccentricity $(\varepsilon)$, latus rectum $(\mathrm{LR})$, angle of major axis $\left(\theta_{\mathrm{m}}{ }^{\circ}\right)$, and orientation angle $\left(\theta_{0}{ }^{\circ}\right)$ of extended park's current data pattern (locus). The extracted parameters are listed in 'Table 4.' The extended park's current data patterns, presented in terms of simplified electrical variables in two-phase machine model form (refer 'Table 3') and extracted mathematical parameters (refer 'Table 4') of selected number of combinations of unbalanced three phase stator currents, are used to analyze and distinguish various states of degradation of stator groundwall insulation of respective phases for the induction motor under test. The performance analysis of simulated electrical variables in twophase machine model form and extracted mathematical parameters are detailed with the support of graphical representations in the following sections.

Table 3. Simulation results of electrical variables in equivalent two-phase machine model ('dq') form for intermediate state of degradation of insulation present in 'phase-a' with equal variation in state of degradation of insulation in 'phase-b' and 'phase-c'

\begin{tabular}{|c|c|c|c|c|c|c|c|c|c|c|}
\hline No. & $\begin{array}{c}\text { per_xd } \\
(\%)\end{array}$ & $\mathrm{Z}_{\mathrm{a}}(\Omega)$ & $\mathrm{Z}_{\mathrm{b}}(\Omega)$ & $\mathrm{Z}_{\mathrm{c}}(\Omega)$ & $\mathrm{I}_{\mathrm{d}}(\mathrm{A})$ & $\beta_{\mathrm{d}}\left({ }^{\circ}\right)$ & $\mathrm{I}_{\mathrm{q}}(\mathrm{A})$ & $\beta_{\mathrm{q}}\left({ }^{\circ}\right)$ & $\mathrm{I}_{\mathrm{dq}}(\mathrm{A})$ & $\beta_{\mathrm{dq}}\left({ }^{\circ}\right)$ \\
\hline 1 & 0.00 & 36.7698 & 36.7698 & 36.7698 & 6.5162 & 360 & 6.5162 & 90 & 9.2153 & 45 \\
\hline 4001 & 19.8034 & 24.1575 & 36.7698 & 36.7698 & 5.8185 & 354.73 & 9.3366 & 93.2813 & 10.2407 & 59.0966 \\
\hline 4106 & 24.7789 & 24.1575 & 30.0627 & 30.0627 & 7.3848 & 0.1225 & 9.8054 & 89.9077 & 12.2973 & 53.0011 \\
\hline 4169 & 30.3925 & 24.1575 & 26.3873 & 26.3873 & 8.7957 & 0.9501 & 9.9179 & 89.1574 & 13.4606 & 48.3798 \\
\hline 4211 & 34.3005 & 24.1575 & 24.1575 & 24.1575 & 9.9182 & 0 & 9.9182 & 90 & 14.0265 & 45 \\
\hline 4253 & 37.9954 & 24.1575 & 22.167 & 22.167 & 11.1046 & 357.62 & 9.9329 & 92.6515 & 14.2359 & 41.6603 \\
\hline 4316 & 42.5971 & 24.1575 & 19.7858 & 19.7858 & 12.618 & 351.237 & 10.4371 & 100.6138 & 13.4452 & 38.3166 \\
\hline 4400 & 45.8122 & 24.1575 & 18.166 & 18.166 & 12.640 & 338.480 & 13.2797 & 110.4353 & 10.5681 & 47.6264 \\
\hline
\end{tabular}


Table 4. Simulation results of extracted mathematical parameters for intermediate state of degradation of insulation present in 'phase-a' with equal variation in state of degradation of insulation in 'phase-b' and 'phase-c'

\begin{tabular}{|c|c|c|c|c|c|c|c|c|c|c|}
\hline No. & $\begin{array}{c}\text { per_xd } \\
(\%)\end{array}$ & $\mathrm{Z}_{\mathrm{a}}(\Omega)$ & $\mathrm{Z}_{\mathrm{b}}(\Omega)$ & $\mathrm{Z}_{\mathrm{c}}(\Omega)$ & $\theta_{0}\left(^{\circ}\right)$ & $\theta_{\mathrm{m}}\left(^{\circ}\right)$ & $\mathrm{L}_{\mathrm{MA}}(\mathrm{A})$ & $\mathrm{L}_{\mathrm{MB}}(\mathrm{A})$ & $\varepsilon$ & $\mathrm{LR}(\mathrm{A})$ \\
\hline 1 & 0.00 & 36.7698 & 36.7698 & 36.7698 & 90 & 90 & 13.0325 & 13.0325 & 0 & 13.0325 \\
\hline 4001 & 19.8034 & 24.1575 & 36.7698 & 36.7698 & 93.2813 & 98.776 & 18.8003 & 11.4305 & 0.7939 & 6.9496 \\
\hline 4106 & 24.7789 & 24.1575 & 30.0627 & 30.0627 & 89.9077 & 89.9077 & 19.6109 & 14.7695 & 0.6579 & 11.1233 \\
\hline 4169 & 30.3925 & 24.1575 & 26.3873 & 26.3873 & 89.1574 & 82.7901 & 19.8709 & 17.5518 & 0.4688 & 15.5034 \\
\hline 4211 & 34.3005 & 24.1575 & 24.1575 & 24.1575 & 90 & 90 & 19.8365 & 19.8365 & 0 & 19.8365 \\
\hline 4253 & 37.9954 & 24.1575 & 22.167 & 22.167 & 92.6515 & -19.6995 & 22.5069 & 19.528 & 0.4972 & 16.9433 \\
\hline 4316 & 42.5971 & 24.1575 & 19.7858 & 19.7858 & 100.6138 & -30.4165 & 27.1653 & 18.2948 & 0.7392 & 12.3209 \\
\hline 4400 & 45.8122 & 24.1575 & 18.166 & 18.166 & 110.4353 & -46.9731 & 33.5011 & 14.9055 & 0.8956 & 6.6318 \\
\hline
\end{tabular}

The graphical representations of an extended park's current data pattern, for a particular class of equal variation in the state of degradation of insulation, occurring in all the three respective phases are in the circular form with centre at the origin over a dq plane. The ideal condition refers to zero percent ('0\%') state of degradation of stator groundwall insulation, occurring in all the three respective phases. The associated electrical variables and extracted mathematical parameters for this state of reference are presented by the combination 'no. 1' in the 'Table 2, Table 3, and Table 4.' The extended park's current data pattern representation over a dq-plane is as illustrated in Fig. 4. The variations are observed with respect to circular extended park's current data pattern corresponding to combination'no.1' as a state of reference.

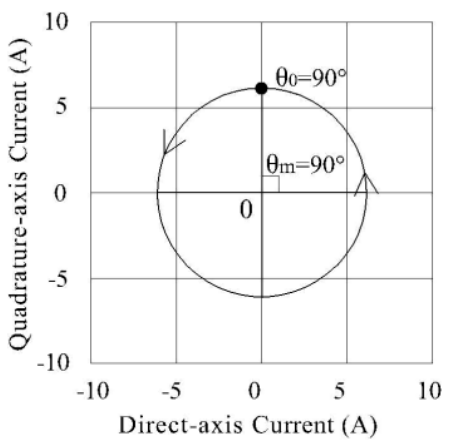

Fig 4: Circular Extended Park's Current Data Pattern as a Reference to Simulate Zero-Percent of State of Degradation.

\section{INTERMEDIATE STATE OF DEGRADATION OF INSULATION PRESENT IN ANY ONE-PHASE WITH EQUAL VARIATION IN STATE OF DEGRADATION IN OTHER TWO- PHASES}

The graphical representations of extended park's current data pattern for intermediate state of degradation of insulation present in any one-phase with an equal variation in the state of degradation, occurring in other two-phases are in an elliptic form with centre at origin over a dq-plane. In the present work, the ' $50 \%$ ' reduction in the real part of steady-state motor impedance per-phase is considered to represent an arbitrary intermediate state of degradation of stator groundwall insulation of the respective phase. The corresponding absolute value of motor impedance per-phase
(Refer 'Table 1') for the induction motor under test is computed as '24.1575( $\Omega)$.' The magnitude of stator current per phase, corresponding to combination 'no. 1' under 'Table 2 ,' is considered as reference value to represent the zeropercent (' $0 \%$ ') state of degradation of insulation (viz., 'a healthy state'). In the following discussion, it is assumed that, if the change in the value of stator current per-phase is within ' $25 \%$ ' of the reference value then the value of stator current per-phase is considered in the low range (L). Similarly, if the change in the value is from ' $25 \%$ ' to ' $60 \%$ ' of the reference value then the value of stator current per-phase is considered in the medium range (M). Further, if the change in the value is above ' $60 \%$ ' of the reference value then the value of stator current per-phase is considered in the high range $(\mathrm{H})$.

The variations in the phase-shift displacements of electrical variables are measured with respect to reference with anticlockwise sense as positive. Any variation in phase-shift around and below ' $10^{\circ}$ ' in either direction is considered as negligible change in the phase-shift. Similarly, any variation in phase-shift within ' $10^{\circ}$ ' to ' $30^{\circ}$ ' in either direction is considered as moderate change in the phase-shift. Further, any variation in phase-shift over and above ' $30^{\circ}$ ' in either direction is considered as significant change in the phaseshift. The variation in the phase-shift displacement of quadrature-axis current is measured with respect to positive 'q-axis,' $\left(+90^{\circ}\right)$, with anticlockwise sense as positive over a dq-plane, as shown in the Fig. 3.

\subsection{Intermediate State of Degradation of Insulation Present in 'Phase-a' with Equal Variation in State of Degradation of Insulation in 'Phase-b' and 'Phase-c'}

An intermediate state of degradation of insulation, present in 'phase-a' and equal variation in the state of degradation in 'phase-b' and 'phase-c,' will introduce the change in the shape of extended park's current data pattern from circular to elliptical form. The simulation results in 'Table 2,' inferred that the magnitudes of all the three phase currents $\left(\mathrm{I}_{\mathrm{a}}, \mathrm{I}_{\mathrm{b}}\right.$, and $I_{c}$ ) are different and not displaced in time with each other by $120^{\circ}$. Similarly, the simulation results in 'Table 3,' inferred that the magnitudes of direct-axis and quadrature-axis current are not equal and not displaced in time with each other by $90^{\circ}$. The resultant dq-axis current phasor $\left(\mathrm{I}_{\mathrm{dq}}\right)$ is not displaced in time by ' $+45.0^{\circ}$ ' with respect to reference. The variations of electrical variables in either form are unlike to the case of equal variation in the state of degradation of insulation in all three phases. 


\subsubsection{Equal Variation in State of Degradation of Insulation in 'Phase-b' and 'Phase-c' from Healthy to Intermediate State}

It is imperative that, any equal variation in the state of degradation of insulation in 'phase-b' and 'phase-c' from healthy to intermediate state is always less than intermediate state of degradation present in 'phase-a.' The graphical representations of extended park's current data pattern over a dq-plane for the selected no. of combinations from '4001' to '4211' (viz., '4001, 4106, and 4169,' which are simulating ' $19.80 \%, 24.77 \%$, and $30.39 \%$ ' state of degradation of insulation, respectively) under 'Table 2 , Table 3 , and Table 4 ' are presented in Fig. 5.

The performance analysis of electrical variables in the threephase machine model ( $a b c)$ form (Refer 'Table 2'), equivalent two-phase model (dq) form (Refer 'Table 3'), and extracted mathematical parameters (Refer 'Table 4') for an equal variation in the state of degradation of insulation in 'phase-b' and 'phase-c' from healthy to intermediate state with intermediate state of degradation present in 'phase-a' is presented in the 'Table 5.'

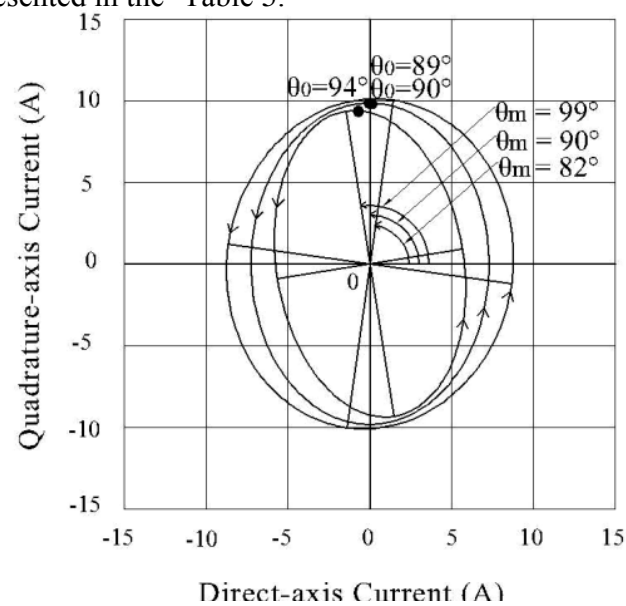

Fig 5: Simulation of Healthy to Intermediate State of Degradation of Insulation in 'Phase-b' and 'Phase-c'

\subsubsection{Equal Variation in State of Degradation of Insulation in 'Phase-b' and 'Phase-c' from Intermediate to Worst-Case State}

It is imperative that, any variations in an equal state of degradation of insulation in 'phase-b' and 'phase-c' from intermediate to worst-case state is always more than intermediate state of degradation present in 'phase-a.' The graphical representations of extended park's current data pattern over a dq-plane for the selected number of combinations from ' 4211 ' to '4400' (viz. , '4253, 4316, and 4400 ,' which are simulating ' $37.99 \%, 42.59 \%$, and $45.81 \%$ ' state of degradation of insulation, respectively) under 'Table 2, Table 3, and Table 4' are presented in Fig. 6.

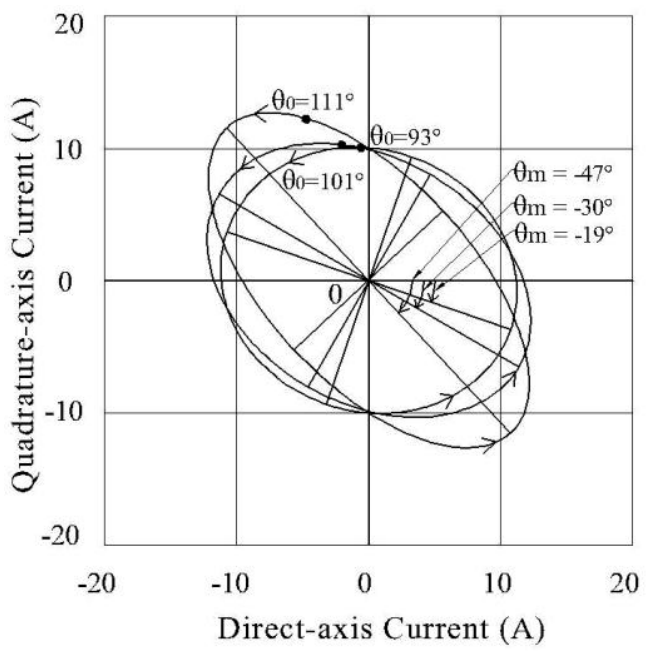

Fig 6: Simulation of Intermediate to Worst-Case State of Degradation of Insulation in 'Phase-b' and 'Phase-c'

Table 5. Performance analysis for equal variation in state of degradation of insulation in 'phase-b' and 'phase-c' from healthy to intermediate state

\begin{tabular}{|c|c|}
\hline $\begin{array}{l}\text { Extracted } \\
\text { Variable/ } \\
\text { Parameter }\end{array}$ & Performance Analysis \\
\hline $\mathrm{I}_{\mathrm{a}}, \mathrm{I}_{\mathrm{b}}, \mathrm{I}_{\mathrm{c}}$ & $\begin{array}{l}\text { The magnitude of current in 'phase-a' experiences negligible increase and varies within a medium range. The magnitude } \\
\text { of current in an affected lagging 'phase-b' experiences moderate increase and varies from low to medium range. The } \\
\text { magnitude of current in an affected leading 'phase-c' experiences negligible increase and varies from low to medium } \\
\text { range. }\end{array}$ \\
\hline$\beta_{\mathrm{a}}, \beta_{\mathrm{b}}, \beta_{\mathrm{c}}$ & $\begin{array}{l}\text { The 'phase-a' and an affected lagging 'phase-b' current phasor experiences negligible phase-shift in clockwise direction } \\
\text { while another affected leading 'phase-c' current phasor experiences moderate phase-shift in clockwise direction. }\end{array}$ \\
\hline $\mathrm{I}_{\mathrm{d}}, \mathrm{I}_{\mathrm{q}}, \mathrm{I}_{\mathrm{dq}}$ & $\begin{array}{l}\text { ' } \mathrm{I}_{\mathrm{d}} \text { ' experiences a moderate rise and varies from low to medium range. ' } \mathrm{I}_{\mathrm{q}} \text { ' experiences a negligible variation (rise) and } \\
\text { varies within a medium range. ' } \mathrm{I}_{\mathrm{dq}} \text { ' experiences moderate rise and varies from low to medium range. }\end{array}$ \\
\hline$\beta_{\mathrm{d}}, \beta_{\mathrm{q}}, \beta_{\mathrm{dq}}$ & $\begin{array}{l}\text { The ' } I_{d} \text { ' phasor experiences negligible phase-shift in either direction. The ' } I_{q} \text { ' phasor experiences negligible phase-shift in } \\
\text { opposite either direction. The ' } I_{d q} \text { ' current phasor does have moderate phase-shift in clockwise direction. }\end{array}$ \\
\hline$\theta_{0}{ }^{\circ}, \theta_{\mathrm{m}}{ }^{\mathrm{o}}$ & $\begin{array}{l}\text { The ' } \theta_{0}{ }^{\circ} \text { ' changes its position over a negligible range }\left(-5.0^{\circ} /+1.0^{\circ}\right) \text { in clockwise direction with respect to positive q- } \\
\text { axis. It is shifted from ' } \theta_{0}^{\circ}=+93.2813^{\circ} \text { ' }\left(+94.0^{\circ}\right) \text { to }{ }^{\circ} \theta_{0}^{\circ}=+89.1574^{\circ} \text { ' }\left(+89.0^{\circ}\right) \text { in clockwise sense and then it is shifted back } \\
\text { to ' } \theta_{0}{ }^{\circ}=+90^{\circ} \text { ' with respect to reference. } \\
\text { The ' } \theta_{\mathrm{m}}{ }^{\circ} \text { ' changes its position over a moderate range }\left(-17.0^{\circ}\right) \text { in clockwise direction with respect to reference. It is shifted } \\
\text { from ' } \theta_{\mathrm{m}}{ }^{\circ}=+98.776^{\circ},\left(+99.0^{\circ}\right) \text { to ' } \theta_{\mathrm{m}}{ }^{\circ}=+82.7901^{\circ},\left(+82.0^{\circ}\right) \text { in clockwise sense with respect to reference. }\end{array}$ \\
\hline
\end{tabular}




\begin{tabular}{|c|l|}
\hline $\mathrm{L}_{\mathrm{MA}}, \mathrm{L}_{\mathrm{MB}}$ & $\begin{array}{l}\text { The ' } \mathrm{L}_{\mathrm{MA}} \text { ' experience negligible change (increase) (18.8003 to 19.8365) while ' } \mathrm{L}_{\mathrm{MB}} \text { ' moderately increases (11.4305 to } \\
19.8365) \text {. }\end{array}$ \\
\hline $\mathrm{LR}$ & $\begin{array}{l}\text { The 'LR' significantly increases (6.9496 to 19.8365) with progressive rise in an equal state of degradation of insulation } \\
\text { in 'phase-b' and 'phase-c'. }\end{array}$ \\
\hline$\varepsilon$ & $\begin{array}{l}\text { The deformation of an elliptic pattern changes with the variation in an eccentricity from } 0.7939 \text { (close to ' } 1 \text { ') to } 0.4688 \\
\text { (close to '0.5') with progressive rise in an equal state of degradation of insulation in 'phase-b' and 'phase-c'. }\end{array}$ \\
\hline
\end{tabular}

The performance analysis of electrical variables in the threephase machine model (abc) form (Refer 'Table 2'), equivalent two-phase model (dq) form (Refer 'Table 3'), and extracted mathematical parameters (Refer 'Table 4') for an equal variation in the state of degradation of insulation in 'phase-b' and 'phase-c' from intermediate to worst-case state with intermediate state of degradation present in 'phase-a' is presented in the 'Table 6.'

\subsection{Intermediate State of Degradation of Insulation Present in 'Phase-b' with Equal Variation in State of Degradation of Insulation in 'Phase-c' and 'Phase-a'}

An intermediate state of degradation of insulation, present in 'phase- $b$ ' and equal variation in the state of degradation in 'phase-c' and 'phase-a,' introduce the change in the shape of extended park's current data pattern from circular to elliptical form. As mentioned in an earlier 'case (4.1),' the simulation results of electrical variables and extracted mathematical parameters for the present case are computed. On account of inadequate space, the simulated results are not shown in the present paper. However, the comparative performance analysis of the same is discussed and presented in the 'section 5.' It is imperative that, any equal variation in the state of degradation of insulation in 'phase-c' and 'phase-a' from healthy to intermediate state is always less than an intermediate state of degradation present in 'phase-b.' The graphical representations of extended park's current data pattern over a dq-plane for the selected number of combinations (viz., '201, 2206, and 3409,' which are simulating ' $19.80 \%, 24.77 \%$, and $30.39 \%$ ' state of degradation of insulation, respectively) are presented in Fig. 7.

Table 6. Performance analysis for equal variation in state of degradation of insulation in 'phase-b' and 'phase-c' from intermediate to worst-case state

\begin{tabular}{|c|c|}
\hline $\begin{array}{l}\text { Extracted } \\
\text { Variable/ } \\
\text { Parameter }\end{array}$ & Performance Analysis \\
\hline $\mathrm{I}_{\mathrm{a}}, \mathrm{I}_{\mathrm{b}}, \mathrm{I}_{\mathrm{c}}$ & $\begin{array}{l}\text { The magnitude of current in 'phase-a' experiences negligible increase and varies from medium to high range. The } \\
\text { magnitude of current in an affected lagging 'phase-b' experiences moderate increase and varies from medium to high } \\
\text { range. The magnitude of current in an affected leading 'phase-c' experiences negligible change (increase / decrease) and } \\
\text { varies from medium to high range. }\end{array}$ \\
\hline$\beta_{\mathrm{a}}, \beta_{\mathrm{b}}, \beta_{\mathrm{c}}$ & $\begin{array}{l}\text { The 'phase-a' experiences negligible phase-shift in clockwise direction. An affected lagging 'phase-b' and leading } \\
\text { 'phase-c' experiences a moderate and a significant phase-shift in clockwise direction, respectively. }\end{array}$ \\
\hline $\mathrm{I}_{\mathrm{d}}, \mathrm{I}_{\mathrm{q}}, \mathrm{I}_{\mathrm{dq}}$ & $\begin{array}{l}\text { The ' } \mathrm{I}_{\mathrm{d}} \text { ' and ' } \mathrm{I}_{\mathrm{q}} \text { ' experience a moderate rise and value varies from medium to high range. The quadrature-axis current } \\
\text { magnitude experiences moderate rise in its value from medium to high range. The ' } \mathrm{I}_{\mathrm{dq}} \text { ' experiences moderate drop in its } \\
\text { value from medium to low range. }\end{array}$ \\
\hline$\beta_{\mathrm{d}}, \beta_{\mathrm{q}}, \beta_{\mathrm{dq}}$ & $\begin{array}{l}\text { The ' } I_{d} \text { ' phasor experiences moderate phase-shift in clockwise direction while the ' } I_{q} \text { ' phasor experiences moderate } \\
\text { phase-shift in anti-clockwise direction. The ' } I_{d q} \text { ' phasor does have negligible phase-shift in either direction. }\end{array}$ \\
\hline$\theta_{0}{ }^{\circ}, \theta_{\mathrm{m}}^{\mathrm{o}}$ & $\begin{array}{l}\text { The ' } \theta_{0}{ }^{\circ} \text { ' changes its position over a moderate range }\left(+21.0^{\circ}\right) \text { in anti-clockwise direction with respect to positive q-axis. } \\
\text { It is shifted from ' } \theta_{0}^{\circ}=90^{\circ} \text { ' to ' } \theta_{0}^{\circ}=+110.4353^{\circ},\left(+111.0^{\circ}\right) \text { in anti-clockwise sense with respect to reference. } \\
\text { The ' } \theta_{\mathrm{m}}{ }^{\circ} \text { ' changes its position over a moderate range }\left(-28.0^{\circ}\right) \text { in clockwise direction with respect to reference. It is shifted } \\
\text { from ' } \theta_{\mathrm{m}}{ }^{\circ}=-19.6995^{\circ},\left(-19.0^{\circ}\right) \text { to }{ }^{\circ} \theta_{\mathrm{m}}{ }^{\circ}=-46.9731^{\circ},\left(-47.0^{\circ}\right) \text { in clockwise sense with respect to reference. }\end{array}$ \\
\hline $\mathrm{L}_{\mathrm{MA}}, \mathrm{L}_{\mathrm{MB}}$ & The 'L $\mathrm{L}_{\mathrm{MA}}$ ' significantly increases (19.8365 to 33.5011) while ' $\mathrm{L}_{\mathrm{MB}}$ ' moderately decreases (19.8365 to 14.9055$)$. \\
\hline
\end{tabular}

Fig 7: Simulation of Healthy to Intermediate State of Degradation of Insulation in 'Phase-c' and 'Phase-a'

Contrary to this, any variations in an equal state of degradation of insulation in 'phase-c' and 'phase-a' from intermediate to worst-case state is always more than intermediate state of degradation present in 'phase-b.' The graphical representations of extended park's current data pattern over a dq-plane for the selected number of combinations (viz., '5013, 6216, and 7820,' which are simulating ' $37.99 \%, 42.59 \%$, and $45.81 \%$ ' state of degradation of insulation, respectively) are presented in Fig. 8.

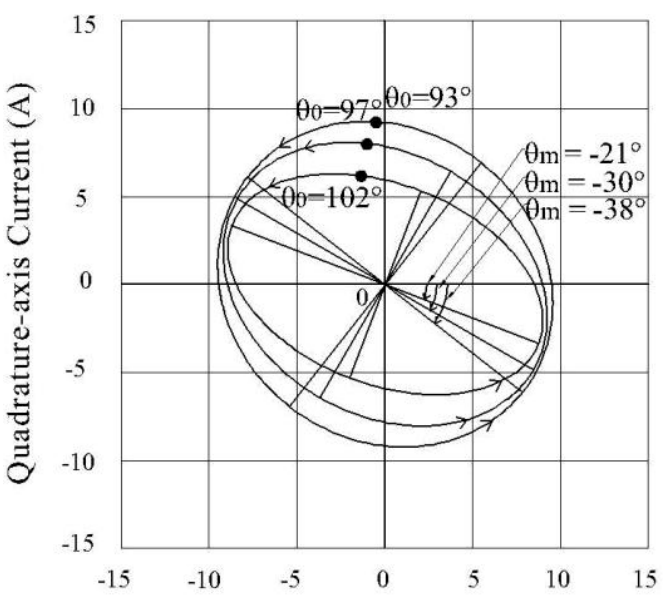

Direct-axis Current (A) 


\begin{tabular}{|c|l|}
\hline LR & $\begin{array}{l}\text { The 'LR' significantly decreases (19.8365 to 6.6318) with progressive rise in an equal state of degradation of insulation } \\
\text { in 'phase-b' and 'phase-c'. }\end{array}$ \\
\hline$\varepsilon$ & $\begin{array}{l}\text { The deformation of an elliptic pattern changes with the variation in an eccentricity from 0.4972 (close to '0.5') to 0.8956 } \\
\text { (close to '1') with progressive rise in an equal state of degradation in 'phase-b' and 'phase-c'. }\end{array}$ \\
\hline
\end{tabular}

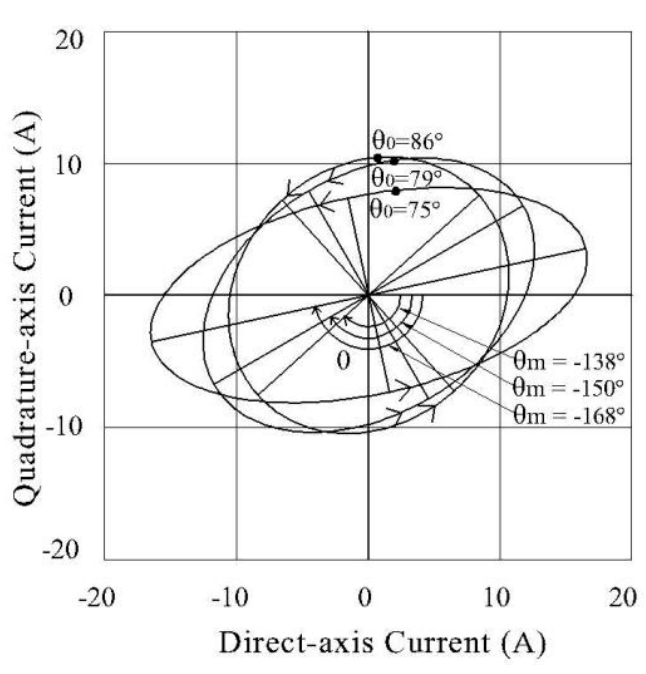

Fig 8: Simulation of Intermediate to Worst-Case State of Degradation of Insulation in 'Phase-c' and 'Phase-a'

\subsection{Intermediate State of Degradation of Insulation Present in 'Phase-c' with Equal Variation in State of Degradation of Insulation in 'Phase-a' and 'Phase-b'}

An intermediate state of degradation of insulation, present in 'phase-c' and equal variation in the state of degradation in 'phase-a' and 'phase-b,' introduces the change in the shape of extended park's current data pattern from circular to elliptical form. As mentioned in an earlier 'case (4.1),' the simulation results of electrical variables and extracted mathematical parameters for the present case are computed. On account of inadequate space, the simulated results are not shown in the present paper. However, the comparative performance analysis of the same is discussed and presented in the 'section 5.' It is imperative that, any equal variation in the state of degradation of insulation in 'phase-a' and 'phase-b' from healthy to intermediate state is always less than an intermediate state of degradation present in 'phase-c.' The graphical representations of extended park's current data pattern over a dq-plane for the selected number of combinations (viz., '11, 2111, and 3371', which are simulating ' $19.80 \%, \quad 24.77 \%$, and $30.39 \%$ ' state of degradation of insulation, respectively) are presented in Fig. 9.

Contrary to this, any variations in an equal state of degradation of insulation in 'phase-a' and 'phase-b' from intermediate to worst-case state is always more than intermediate state of degradation present in 'phase-c.' The graphical representations of extended park's current data pattern over a dq-plane for the selected number of combinations (viz., '5051, 6311, and 7991,' which are simulating ' $37.99 \%, \quad 42.59 \%$, and $45.81 \%$ ' state of degradation of insulation, respectively) are presented in Fig. 10.

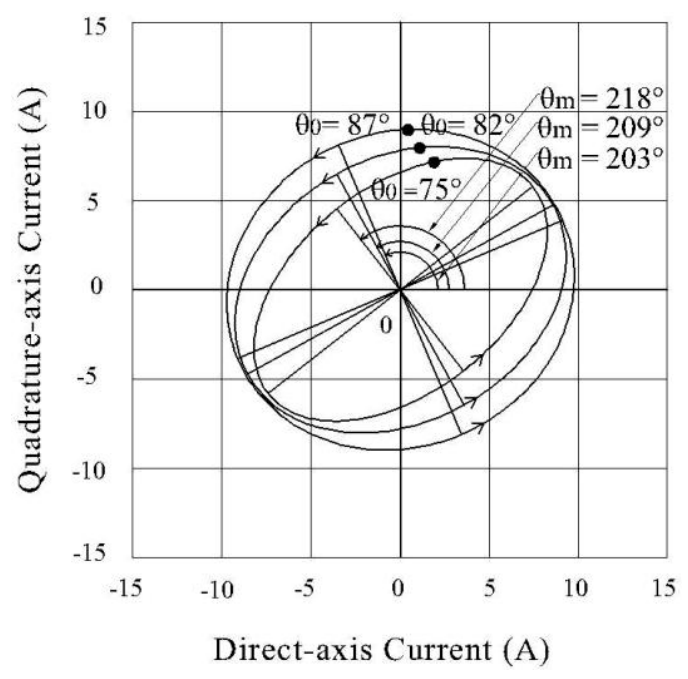

Fig 9: Simulation of Healthy to Intermediate State of Degradation of Insulation in 'Phase-a' and 'Phase-b'

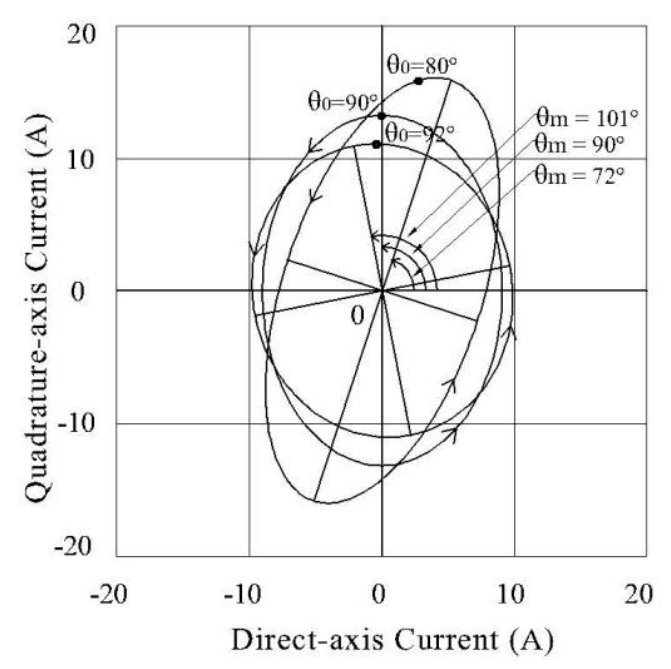

Fig 10: Simulation of Intermediate to Worst-Case State of Degradation in 'Phase-a' and 'Phase-b'

\section{DISCUSSION ON PERFORMANCE ANALYSIS}

The progressive rise in an equal state of degradation of insulation in all the three-phases results into the significant increase in the magnitudes of three-phase currents. Further, all the three-phase current phasors experiences a significant phase-shift in the clockwise direction but are still displaced in time with each other by $120^{\circ}$. In an equivalent two-phase (dq) model, the magnitudes of both direct-axis and quadrature-axis current significantly increases and are equal. However, there is no change in the phase-shift ( $\beta_{\mathrm{d}}=0^{\circ}$ ' and ' $\beta_{\mathrm{q}}=+90^{\circ}$ ') for either one of them. The quadrature-axis current phasor is always leading in quadrature with direct-axis current phasor 
over a dq-plane. Hence, the extended park's current data pattern appears in the circular form with significant rise in its radius.

If intermediate state of degradation of insulation is present in any one-phase and an equal variation in the state of degradation of insulation in other two-phases progressively increases from healthy to intermediate state (viz., 'part-(1),' of 'case (4.1)' under 'section 4') then the extended parks current data pattern appears in elliptic form. The magnitudes of all the three phase currents $\left(I_{a}, I_{b}\right.$, and $\left.I_{c}\right)$ are different and they are not displaced in time with each other by $120^{\circ}$. The magnitude of current in an intermediate state 'degraded-phase' experiences a negligible increase in its value and varies within a medium range. The magnitude of current in an affected 'lagging-phase' experiences a moderate increase in its value and varies from low to medium range. The magnitude of current in affected 'leading-phase' experiences a negligible increase in its value and varies from low to medium range. An intermediate state 'degraded-phase' and affected 'laggingphase' current phasors experience a negligible phase- shift in clockwise direction while another affected 'leading-phase' current phasor experiences a moderate phase-shift in clockwise direction.

The comparative performance analysis of simulated electrical variables in equivalent two-phase dq-model form is detailed in 'Table 7' The changes in magnitudes and phase-shift angles of 'direct-axis,' 'quadrature-axis,' and resultant 'dq-axis' currents are varying over a different range in a distinct manner to distinguish the presence of intermediate state of degradation of insulation in any one particular phase (i.e., a, b, and c) and equal variation in the state of degradation of insulation (from healthy to intermediate state ) in other twophases (i.e., b-c, c-a, and a-b ), respectively.

Similarly, the comparative performance analyses of corresponding simulated extracted parameters are detailed in 'Table 8.' With reference to 'Table 8(a),' it is observed that an extracted parameter like angle of orientation $\left(\theta_{0}^{\circ}\right)$ of an elliptic pattern (locus), changes its position over a variable range. It is changing over a different zones (viz., ' $+94.0^{\circ}$ to $+89.0^{\circ}$ to $+90.0^{\circ},+102.0^{\circ}$ to $+90.0^{\circ}$, and $+75.0^{\circ}$ to $+90.0^{\circ}$ ') in a dqplane, for intermediate state of degradation of insulation present in any one-phase (viz., a, b, and c) and an equal variation in the state of degradation of insulation (from healthy to intermediate state) in other two-phases (viz., b-c, ca, and a-b), respectively. This is illustrated in Fig. 11.

With reference to 'Table 8(a),' it is observed that an extracted parameter like angle of major-axis $\left(\theta_{\mathrm{m}}{ }^{\circ}\right)$ of an elliptic pattern, changes its position over a moderate range $\left(-17.0^{\circ}\right)$, which is identical irrespective of intermediate state of degradation of insulation present in any one-phase (viz., a, b, and c) and an equal variation in the state of degradation of insulation (from healthy to intermediate state) in other two-phases (viz., b-c, c$\mathrm{a}$, and $\mathrm{a}-\mathrm{b})$, respectively. However, ' $\theta_{\mathrm{m}}{ }^{\circ}$ ' is changing over a distinct zones (viz., ' $+99.0^{\circ}$ to $+82.0^{\circ},-21.0^{\circ}$ to $-38.0^{\circ}$, and $+218.0^{\circ}$ to $+203.0^{\circ}$ ) ) in a dq-plane, for intermediate state of degradation of insulation present in any one-phase (viz., a, b, and c) and an equal variation in the state of degradation of insulation (from healthy to intermediate state) in other twophases (viz., b-c, c-a, and a-b), respectively. This is illustrated in Fig. 12.

Table 7. Comparative performance analyses of simulated electrical variables in equivalent two-phase (dq) model form for intermediate state of degradation of insulation present in any one-phase and equal variation in state of degradation from healthy to intermediate state in other two-phases.

\begin{tabular}{|c|c|c|c|c|c|c|c|}
\hline \multirow{2}{*}{$\begin{array}{l}\text { Intermediate } \\
\text { Degraded } \\
\text { Phase }\end{array}$} & \multirow{2}{*}{$\begin{array}{l}\text { Variation } \\
\text { in } \\
\text { Degraded } \\
\text { Phases }\end{array}$} & \multicolumn{3}{|c|}{ Magnitude of Currents (A) } & \multicolumn{3}{|c|}{ Phase Shift of Currents $\left(^{\circ}\right)$} \\
\hline & & $\mathrm{I}_{\mathrm{d}}(\mathrm{A})$ & $\mathrm{I}_{\mathrm{q}}(\mathrm{A})$ & $\mathrm{I}_{\mathrm{dq}}(\mathrm{A})$ & $\beta_{\mathrm{d}}\left({ }^{\circ}\right)$ & $\beta_{\mathrm{q}}\left({ }^{\circ}\right)$ & $\beta_{\mathrm{dq}}\left({ }^{\circ}\right)$ \\
\hline $\begin{array}{c}\mathrm{a} \\
(\mathrm{a}>\mathrm{b}-\mathrm{c})\end{array}$ & b-c & $\begin{array}{c}(\mathrm{M}) \\
\text { Negligible } \\
\text { Decrease } \\
(11.18 \rightarrow 9.91) \\
(\downarrow) \\
\end{array}$ & $\begin{array}{c}(\mathrm{L} \text { to } \mathrm{M}) \\
\text { Moderate } \\
\text { Increase } \\
(6.2 \rightarrow 9.91) \\
(\uparrow) \\
\end{array}$ & $\begin{array}{c}(\mathrm{M}) \\
\text { Negligible } \\
\text { Increase } \\
(12.35 \rightarrow 14.02) \\
(\uparrow) \\
\end{array}$ & $\begin{array}{l}\text { Negligible } \\
\quad \text { (anti- } \\
\text { clockwise) } \\
\left(-2^{\circ} \rightarrow 0^{\circ}\right)\end{array}$ & $\begin{array}{c}\text { Negligible } \\
(\text { clockwise }) \\
\left(+93^{\circ} \rightarrow+90^{\circ}\right)\end{array}$ & $\begin{array}{c}\text { Moderate } \\
(\text { anti- } \\
\text { clockwise }) \\
\left(+28^{\circ} \rightarrow+45^{\circ}\right)\end{array}$ \\
\hline $\begin{array}{c}b \\
(b>c-a)\end{array}$ & $\mathrm{c}-\mathrm{a}$ & $\begin{array}{c}(\mathrm{M}) \\
\text { Negligible } \\
\text { Increase } \\
(8.05 \rightarrow 9.91) \\
(\uparrow) \\
\end{array}$ & $\begin{array}{c}(\mathrm{M}) \\
\text { Negligible } \\
\text { Change } \\
(9.93 \rightarrow 9.71 \rightarrow 9.91) \\
(\downarrow \uparrow) \\
\end{array}$ & $\begin{array}{c}\mathrm{H} \text { to } \mathrm{M}) \\
\text { Negligible } \\
\text { Decrease } \\
(15.62 \rightarrow 14.02) \\
(\downarrow)\end{array}$ & $\begin{array}{c}\text { Moderate } \\
\text { (clockwise) } \\
\left(+17^{\circ} \rightarrow 0^{\circ}\right)\end{array}$ & $\begin{array}{c}\text { Moderate } \\
(\text { anti-clockwise) } \\
\left(+76^{\circ} \rightarrow+90^{\circ}\right)\end{array}$ & $\begin{array}{c}\text { Negligible } \\
\text { (clockwise) } \\
\left(+50^{\circ} \rightarrow 45^{\circ}\right)\end{array}$ \\
\hline $\begin{array}{c}c \\
(c>a-b)\end{array}$ & $a-b$ & $\begin{array}{c}(\mathrm{L} \text { to } \mathrm{M}) \\
\text { Moderate } \\
\text { Increase } \\
(7.44 \rightarrow 9.91) \\
(\uparrow)\end{array}$ & $\begin{array}{c}(\mathrm{M}) \\
\text { Negligible } \\
\text { Change } \\
(10.4 \rightarrow 9.91) \\
(\downarrow)\end{array}$ & $\begin{array}{c}(\mathrm{L} \text { to } \mathrm{M}) \\
\text { Moderate } \\
\text { Increase } \\
(9.7 \rightarrow 14.02) \\
(\uparrow)\end{array}$ & $\begin{array}{c}\begin{array}{c}\text { Moderate } \\
(\text { anti- }\end{array} \\
\text { clockwise) } \\
\left(-16^{\circ} \rightarrow 0^{\circ}\right)\end{array}$ & $\begin{array}{c}\text { Moderate } \\
(\text { clockwise }) \\
\left(+101^{\circ} \rightarrow+90^{\circ}\right)\end{array}$ & $\begin{array}{c}\text { Moderate } \\
(\text { clockwise }) \\
\left(+58^{\circ} \rightarrow+45^{\circ}\right)\end{array}$ \\
\hline
\end{tabular}




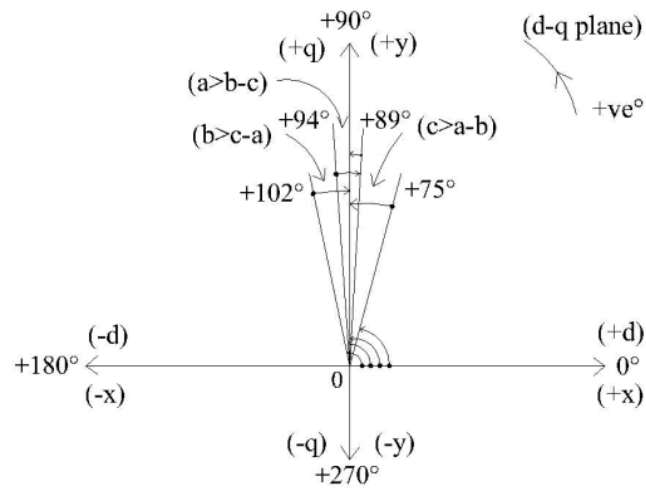

Fig 11: Different Zones of Angle of Orientation $\left(\theta_{0}^{\circ}\right)$ for Healthy to Intermediate State of Degradation of Insulation in Affected Phases

With reference to 'Table 8(b),' it is observed that the changes in an extracted parameters like ' $\mathrm{L}_{\mathrm{MA}}, \mathrm{L}_{\mathrm{MB}}, \mathrm{LR}$, and $\varepsilon$ ' are identical, which occur irrespective of intermediate state of degradation of insulation present in any one-phase (viz., a, b, and c) and an equal variation in the state of degradation of insulation (from healthy to intermediate state) in other twophases (viz., b-c, c-a, and a-b), respectively.

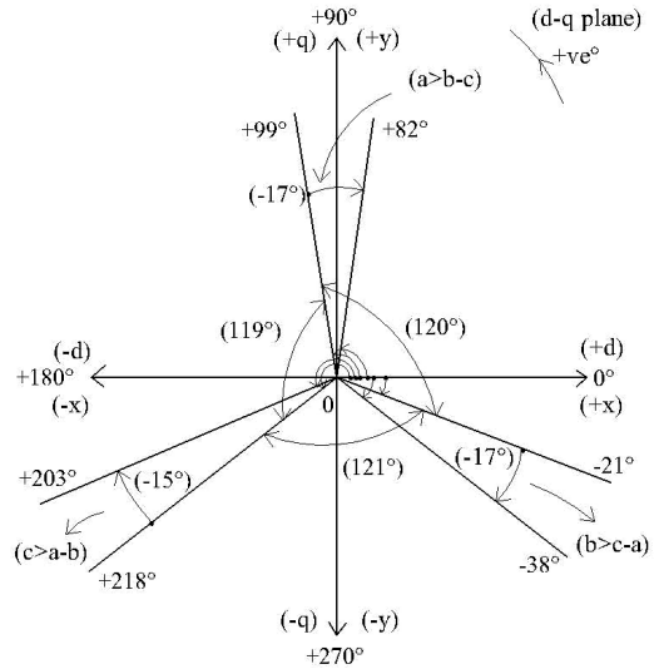

Fig 12: Distinct Zones of Angle of Major-Axis $\left(\theta_{m}{ }^{\circ}\right)$ for Healthy to Intermediate State of Degradation of Insulation in Affected Phases

Table 8. Comparative performance analyses of extracted parameters for intermediate state of degradation of insulation present in any one-phase and equal variation in state of degradation from healthy to intermediate state in other two-phases.

Table 8(a). Extracted parameters ' $\theta_{0}\left({ }^{\circ}\right)$ ' and ' $\theta_{\mathrm{m}}\left({ }^{\circ}\right)$ '

\begin{tabular}{|c|c|c|c|c|c|}
\hline $\begin{array}{c}\text { Inter- } \\
\text { Mediate } \\
\begin{array}{c}\text { Degraded } \\
\text { Phase }\end{array}\end{array}$ & $\begin{array}{c}\text { Variation } \\
\text { in } \\
\text { Degraded } \\
\text { Phases }\end{array}$ & $\begin{array}{c}\text { Angle of Orientation } \\
\left(\theta_{0}^{\circ}\right)\end{array}$ & $\begin{array}{c}\text { Range of Angle of Orientation } \\
\left(\theta_{0}^{\circ}\right)\end{array}$ & $\begin{array}{c}\text { Angle of Major-Axis } \\
\left(\theta_{\mathrm{m}}{ }^{\circ}\right)\end{array}$ & $\begin{array}{c}\text { Range of Angle of } \\
\text { Major-Axis }\end{array}$ \\
\hline $\begin{array}{c}\mathrm{a} \\
(\mathrm{a}>\mathrm{b}-\mathrm{c})\end{array}$ & $\mathrm{b}-\mathrm{c}$ & $\begin{array}{c}\left(+94.0^{\circ}\right) \text { to }\left(+89.0^{\circ}\right) \\
\left(+89.0^{\circ}\right) \text { to }\left(+90.0^{\circ}\right)\end{array}$ & $\begin{array}{c}\text { Negligible } \\
\left(-5.0^{\circ} /+1.0^{\circ}\right) \text { clockwise }\end{array}$ & $\left(+99.0^{\circ}\right)$ to $\left(+82.0^{\circ}\right)$ & $\begin{array}{c}\text { Moderate }\left(-17.0^{\circ}\right) \\
\text { clockwise }\end{array}$ \\
\hline $\begin{array}{c}\mathrm{b} \\
(\mathrm{b}>\mathrm{c}-\mathrm{a})\end{array}$ & $\mathrm{c}-\mathrm{a}$ & $\left(+102.0^{\circ}\right)$ to $\left(+90.0^{\circ}\right)$ & $\begin{array}{c}\text { Moderate } \\
\left(-12.0^{\circ}\right) \text { clockwise }\end{array}$ & $\left(-21.0^{\circ}\right)$ to $\left(-38.0^{\circ}\right)$ & $\begin{array}{c}\text { Moderate } \\
\left(-17.0^{\circ}\right) \\
\text { clockwise }\end{array}$ \\
\hline $\begin{array}{c}\mathrm{c} \\
(\mathrm{c}>\mathrm{a}-\mathrm{b})\end{array}$ & $\mathrm{a}-\mathrm{b}$ & $\left(+75.0^{\circ}\right)$ to $\left(+90.0^{\circ}\right)$ & $\begin{array}{c}\text { Moderate } \\
\left(+15.0^{\circ}\right) \text { anti-clockwise }\end{array}$ & $\left(+218.0^{\circ}\right)$ to $\left(+203.0^{\circ}\right)$ & $\begin{array}{c}\text { Moderate } \\
\text { clockwise }\end{array}$ \\
\hline
\end{tabular}

Table 8(b). Extracted parameters ' $\mathrm{L}_{\mathrm{MA}}, \mathrm{L}_{\mathrm{MB}}$, $\varepsilon$, and $\mathbf{L R}$ '

\begin{tabular}{|c|c|c|c|c|c|}
\hline $\begin{array}{c}\text { Inter - } \\
\text { Mediate } \\
\text { Degraded } \\
\text { Phase }\end{array}$ & $\begin{array}{l}\text { Variation } \\
\text { in } \\
\text { Degraded } \\
\text { Phases }\end{array}$ & $\begin{array}{l}\text { Length of Major-Axis } \\
\qquad\left(\mathrm{L}_{\mathrm{MA}}\right)\end{array}$ & $\begin{array}{l}\text { Length of Minor- } \\
\text { Axis }\left(\mathrm{L}_{\mathrm{MB}}\right)\end{array}$ & Eccentricity $(\varepsilon)$ & Latus Rectum (LR) \\
\hline $\begin{array}{c}\mathrm{a} \\
(\mathrm{a}>\mathrm{b}-\mathrm{c})\end{array}$ & $b-c$ & $\begin{array}{c}\text { Negligible Change (Inc.) } \\
(18.8003 \rightarrow 19.8365) \\
(\uparrow)\end{array}$ & $\begin{array}{c}\text { Moderate Increase } \\
(11.4305 \rightarrow 19.8365) \\
(\uparrow)\end{array}$ & $\begin{array}{c}0.7939 \text { (close to ' } 1 \text { ') } \\
\text { to } \\
0.4688 \text { (close to '0.5') }\end{array}$ & $\begin{array}{l}\text { Significant Increase } \\
(6.9496 \rightarrow 19.8365)(\uparrow)\end{array}$ \\
\hline $\begin{array}{c}b \\
(b>c-a)\end{array}$ & $\mathrm{c}-\mathrm{a}$ & $\begin{array}{c}\text { Negligible Change (Inc.) } \\
(18.8009 \rightarrow 19.8365) \\
(\uparrow)\end{array}$ & $\begin{array}{c}\text { Moderate Increase } \\
(11.4295 \rightarrow 19.8365) \\
(\uparrow)\end{array}$ & $\begin{array}{c}0.7940 \text { (close to ' } 1 \text { ') } \\
\text { to } \\
0.4688 \text { (close to '0.5') }\end{array}$ & $\begin{array}{c}\text { Significant Increase } \\
(6.9482 \rightarrow 19.8365)(\uparrow)\end{array}$ \\
\hline $\begin{array}{c}c \\
(c>a-b)\end{array}$ & $a-b$ & $\begin{array}{l}\text { Negligible Change (Inc.) } \\
\quad(18.8002 \rightarrow 19.8365) \\
(\uparrow)\end{array}$ & $\begin{array}{c}\text { Moderate Increase } \\
(11.4307 \rightarrow 19.8365) \\
(\uparrow)\end{array}$ & $\begin{array}{c}0.7939 \text { (close to ' } 1 \text { ') } \\
\text { to } \\
0.4688 \text { (close to ' } 0.5 \text { ') }\end{array}$ & $\begin{array}{c}\text { Significant Increase } \\
(6.9499 \rightarrow 19.8365)(\uparrow)\end{array}$ \\
\hline
\end{tabular}


If intermediate state of degradation of insulation is present in any one-phase and an equal state of degradation of insulation, occurring in other two-phases progressively increases from intermediate to worst-case state (viz., 'part-(2),' of 'case (4.1)' under 'section 4') then the extended parks current data pattern appears in an elliptic form. The magnitude of all the three-phase currents $\left(I_{a}, I_{b}\right.$, and $\left.I_{c}\right)$ are different and they are not displaced in time with each other by $120^{\circ}$. The magnitude of current in an intermediate state 'degraded-phase' experiences negligible increase in its value and varies from medium to high range. The magnitude of current in an affected 'lagging-phase' experiences a moderate increase in its value and varies from medium to high range. The magnitude of current in affected 'leading-phase' experiences a negligible change (increase / decrease) in its value and varies from medium to high range. An intermediate state 'degradedphase' current phasor experiences a negligible phase-shift in clockwise direction. An affected 'lagging-phase' current phasor experiences a moderate phase-shift in clockwise direction while an affected 'leading-phase' current phasor experiences a significant phase-shift in clockwise direction.
The comparative performance analysis of simulated electrical variables in equivalent two-phase (dq) model form is detailed in 'Table 9.' The changes in magnitudes and phase-shift angles of direct-axis, quadrature-axis and resultant dq-axis currents are varying over a different range in a distinct manner to distinguish the presence of intermediate state of degradation of insulation in any one particular phase (i.e., a, b, and c) and an equal variation in the state of degradation of insulation (from intermediate to worst-case state ) in other two-phases (i.e., b-c, c-a, and a-b ), respectively.

Similarly, the comparative performance analyses of corresponding simulated extracted parameters are detailed in 'Table 10.' With reference to 'Table 10(a),' it is observed that the angle of orientation $\left(\theta_{0}^{\circ}\right)$ of an elliptic pattern (locus), changes its position over a variable range. It is changing over a different zones (viz., " $+90.0^{\circ}$ to $+111.0^{\circ},+90.0^{\circ}$ to $+75.0^{\circ}$, and $+90.0^{\circ}$ to $+92.0^{\circ}$ to $+80.0^{\circ}$ ') in a dq-plane, for intermediate state of degradation of insulation present in any one-phase (viz., a, b, and c) and an equal variation in the state of degradation of insulation (from intermediate to worst-case state) in other two-phases (viz., b-c, c-a, and a-b), respectively. This is illustrated in Fig. 13.

Table 9. Comparative performance analyses of simulated electrical variables in equivalent two-phase (dq) model form for intermediate state of degradation of insulation present in any one-phase and equal variation in state of degradation from intermediate to worst-case state in other two-phases.

\begin{tabular}{|c|c|c|c|c|c|c|c|}
\hline \multirow{2}{*}{$\begin{array}{c}\text { Inter- } \\
\text { Mediate } \\
\text { Degraded } \\
\text { Phase }\end{array}$} & \multirow{2}{*}{$\begin{array}{l}\text { Variation } \\
\text { in } \\
\text { Degrade } \\
\text { d Phases }\end{array}$} & \multicolumn{3}{|c|}{ Magnitude of Currents (A) } & \multicolumn{3}{|c|}{ Phase Shift of Currents $\left(^{\circ}\right)$} \\
\hline & & $\mathrm{I}_{\mathrm{d}}(\mathrm{A})$ & $\mathrm{I}_{\mathrm{q}}(\mathrm{A})$ & $\mathrm{I}_{\mathrm{dq}}(\mathrm{A})$ & $\beta_{\mathrm{d}}\left(^{\circ}\right)$ & $\beta_{\mathrm{q}}\left(^{\circ}\right)$ & $\beta_{\mathrm{dq}}\left({ }^{\circ}\right)$ \\
\hline $\mathrm{a}$ & $\begin{array}{c}b-c \\
(b-c>a)\end{array}$ & $\begin{array}{c}(\mathrm{M}) \\
\text { Negligible } \\
\text { Change } \\
(9.91 \rightarrow 9.36) \\
(\downarrow)\end{array}$ & $\begin{array}{c}(\mathrm{M} \text { to } \mathrm{H}) \\
\text { Moderate } \\
\text { Increase } \\
(9.91 \rightarrow 13.24) \\
(\uparrow)\end{array}$ & $\begin{array}{c}(\mathrm{M} \text { to } \mathrm{H}) \\
\text { Significant } \\
\text { Increase } \\
(14.02 \rightarrow 20.15) \\
(\uparrow)\end{array}$ & $\begin{array}{c}\text { Moderate } \\
\text { (anti- } \\
\text { clockwise) } \\
\left(0^{\circ} \rightarrow+18^{\circ}\right)\end{array}$ & $\begin{array}{c}\text { Moderate } \\
(\text { clockwise) } \\
\left(+90^{\circ} \rightarrow+76^{\circ}\right)\end{array}$ & $\begin{array}{c}\text { Negligible } \\
(\text { anti- } \\
\text { clockwise) } \\
\left(+45^{\circ} \rightarrow+53^{\circ}\right)\end{array}$ \\
\hline $\mathrm{b}$ & $\begin{array}{c}c-a \\
(c-a>b)\end{array}$ & $\begin{array}{c}\mathrm{M}) \\
\text { Negligible } \\
\text { Change }(\uparrow \downarrow) \\
(9.91 \rightarrow 10.42 \rightarrow 9.8)\end{array}$ & $\begin{array}{c}(\mathrm{M} \text { to } \mathrm{H}) \\
\text { Moderate } \\
\text { Increase } \\
(9.91 \rightarrow 13.20) \\
(\uparrow)\end{array}$ & $\begin{array}{c}(\mathrm{M}) \\
\text { Moderate } \\
\text { Decrease } \\
(14.02 \rightarrow 11.67) \\
(\downarrow)\end{array}$ & $\begin{array}{c}\text { Moderate } \\
\text { (clockwise) } \\
\left(0^{\circ} \rightarrow-18^{\circ}\right)\end{array}$ & $\begin{array}{c}\text { Moderate } \\
(\text { anti- } \\
\text { clockwise) } \\
\left(+90^{\circ} \rightarrow+104^{\circ}\right)\end{array}$ & $\begin{array}{c}\text { Moderate } \\
\text { (anti- } \\
\text { clockwise) } \\
\left(+45^{\circ} \rightarrow+57^{\circ}\right)\end{array}$ \\
\hline $\mathrm{c}$ & $\begin{array}{c}a-b \\
(a-b>c)\end{array}$ & $\begin{array}{c}(\mathrm{M} \text { to } \mathrm{H}) \\
\text { Moderate } \\
\text { Increase } \\
(9.91 \rightarrow 14.62) \\
(\uparrow)\end{array}$ & $\begin{array}{c}(\mathrm{M} \text { to } \mathrm{L}) \\
\text { Moderate } \\
\text { Decrease } \\
(9.91 \rightarrow 7.62) \\
(\downarrow)\end{array}$ & $\begin{array}{c}(\mathrm{H}) \\
\text { Negligible } \\
\text { Increase } \\
(14.02 \rightarrow 16.52) \\
(\uparrow)\end{array}$ & $\begin{array}{l}\text { Negligible } \\
\quad \text { anti- } \\
\text { clockwise) } \\
\left(+0^{\circ} \rightarrow\right. \\
\left.+2^{\circ} \rightarrow+0^{\circ}\right)\end{array}$ & $\begin{array}{c}\text { Negligible } \\
(\text { clockwise) } \\
\left(+90^{\circ} \rightarrow+89^{\circ}\right)\end{array}$ & $\begin{array}{c}\text { Moderate } \\
(\text { clockwise }) \\
\left(+45^{\circ} \rightarrow+27^{\circ}\right)\end{array}$ \\
\hline
\end{tabular}

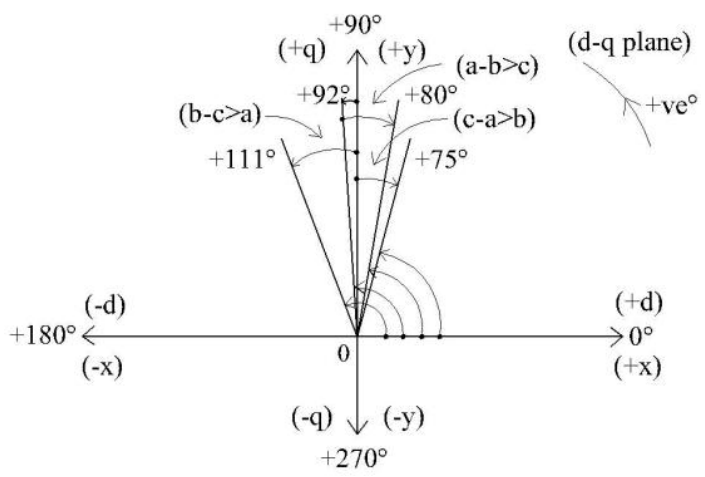

Fig 13: Different Zones of Angle of Orientation $\left(\theta_{0}^{\circ}\right)$ for Intermediate to Worst-Case State of Degradation of Insulation in Affected Phases
With reference to 'Table 10(b),' it is observed that the angle of major-axis $\left(\theta_{\mathrm{m}}{ }^{\circ}\right)$ of an elliptic pattern, changes its position over a significant range $\left(-29.0^{\circ}\right)$, which is identical irrespective of intermediate state of degradation of insulation present in any one-phase (viz., a, b, and c) and an equal variation in the state of degradation of insulation (from intermediate to worst-case state) in other two-phases (viz., b$\mathrm{c}, \mathrm{c}-\mathrm{a}$, and $\mathrm{a}-\mathrm{b}$ ), respectively. However, ' $\theta_{\mathrm{m}}{ }^{\circ}$ ' is changing over distinct zones (viz., ' $-19.0^{\circ}$ to $-47.0^{\circ},-138.0^{\circ}$ to $-168.0^{\circ}$, and $+101.0^{\circ}$ to $+72.0^{\circ}$ ) in a dq-plane, for intermediate state of degradation of insulation present in any one-phase (viz., a, b, and c) and an equal variation in the state of degradation of insulation (from intermediate to worst-case state) in other two-phases (viz., b-c, c-a, and a-b), respectively. This is illustrated in Fig. 14. 


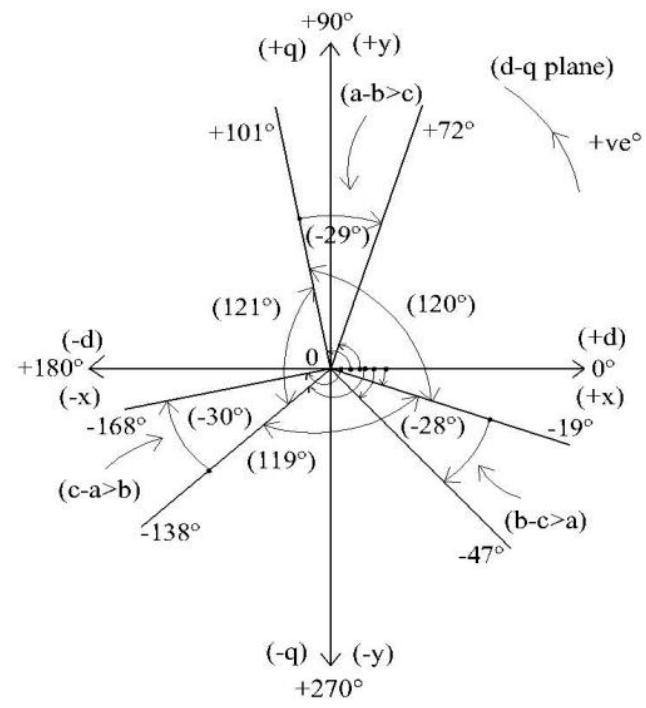

With reference to 'Table 10(b),' it is observed that the changes in the extracted parameters like ' $\mathrm{L}_{\mathrm{MA}}, \mathrm{L}_{\mathrm{MB}}, \mathrm{LR}$, and $\varepsilon$ ' are identical, which occur irrespective of intermediate state of degradation of insulation present in any one-phase (viz., a, $\mathrm{b}$, and c) and equal variation in the state of degradation of insulation (from intermediate to worst-case state) in other two-phases (viz., b-c, c-a, and a-b), respectively.

Fig 14: Distinct Zones of Angle of Major-Axis $\left(\theta_{m}{ }^{\circ}\right)$ for Intermediate to Worst-Case State of Degradation of Insulation in Affected Phases

Table 10. Comparative performance analyses of extracted parameters for intermediate state of degradation of insulation present in any one-phase and equal variation in state of degradation from intermediate to worst-case state in other two-phases.

Table 10(a). Extracted parameters ' $\theta_{0}\left({ }^{\circ}\right)$ ' and ' $\theta_{m}\left({ }^{\circ}\right)$

\begin{tabular}{|c|c|c|c|c|c|}
\hline $\begin{array}{c}\text { Inter- } \\
\text { Mediate } \\
\text { Degraded } \\
\text { Phase }\end{array}$ & $\begin{array}{c}\text { Variation } \\
\text { in } \\
\text { Degraded } \\
\text { Phases }\end{array}$ & $\begin{array}{l}\text { Angle of Orientation } \\
\qquad\left(\theta_{0}^{\circ}\right)\end{array}$ & $\begin{array}{l}\text { Range of Angle of } \\
\text { Orientation }\left(\theta_{0}^{\circ}\right)\end{array}$ & $\begin{array}{l}\text { Angle of Major-Axis } \\
\qquad\left(\theta_{\mathrm{m}}{ }^{\mathrm{o}}\right)\end{array}$ & $\begin{array}{l}\text { Range of Angle of } \\
\text { Major-Axis }\left(\theta_{m}{ }^{\circ}\right)\end{array}$ \\
\hline $\mathrm{a}$ & $\begin{array}{c}b-c \\
(b-c>a)\end{array}$ & $\left(+90.0^{\circ}\right)$ to $\left(+111.0^{\circ}\right)$ & $\begin{array}{c}\text { Moderate } \\
\left(+21.0^{\circ}\right) \text { anti-clockwise }\end{array}$ & $\left(-19.0^{\circ}\right)$ to $\left(-47.0^{\circ}\right)$ & $\begin{array}{c}\text { Significant }\left(-28.0^{\circ}\right) \\
\text { clockwise }\end{array}$ \\
\hline $\mathrm{b}$ & $\begin{array}{c}c-a \\
(c-a>b)\end{array}$ & $\left(+90.0^{\circ}\right)$ to $\left(+75.0^{\circ}\right)$ & $\begin{array}{c}\text { Moderate } \\
\left(-15.0^{\circ}\right) \text { clockwise } \\
\end{array}$ & $\left(-138.0^{\circ}\right)$ to $\left(-168.0^{\circ}\right)$ & $\begin{array}{c}\text { Significant }\left(-30.0^{\circ}\right) \\
\text { clockwise }\end{array}$ \\
\hline $\mathrm{c}$ & $\begin{array}{c}a-b \\
(a-b>c)\end{array}$ & $\begin{array}{l}\left(+90.0^{\circ}\right) \text { to }\left(+92.0^{\circ}\right) \\
\left(+92.0^{\circ}\right) \text { to }\left(+80.0^{\circ}\right)\end{array}$ & $\begin{array}{c}\text { Moderate } \\
\left(+2.0^{\circ} /-12.0^{\circ}\right) \text { clockwise }\end{array}$ & $\left(+101.0^{\circ}\right)$ to $\left(+72.0^{\circ}\right)$ & $\begin{array}{c}\text { Significant }\left(-29.0^{\circ}\right) \\
\text { clockwise }\end{array}$ \\
\hline
\end{tabular}

Table 10(b). Extracted parameters ' $\mathrm{L}_{\mathrm{MA}}, \mathrm{L}_{\mathrm{MB}}, \varepsilon$, and $\mathrm{LR}$ '

\begin{tabular}{|c|c|c|c|c|c|}
\hline $\begin{array}{c}\text { Inter- } \\
\text { Mediate } \\
\text { Degraded } \\
\text { Phase }\end{array}$ & $\begin{array}{c}\text { Variation } \\
\text { in } \\
\text { Degraded } \\
\text { Phases }\end{array}$ & $\begin{array}{l}\text { Length of Major-Axis } \\
\qquad\left(\mathrm{L}_{\mathrm{MA}}\right)\end{array}$ & $\begin{array}{l}\text { Length of Minor-Axis } \\
\qquad\left(\mathrm{L}_{\mathrm{MB}}\right)\end{array}$ & Eccentricity $(\varepsilon)$ & Latus Rectum (LR) \\
\hline $\mathrm{a}$ & $\begin{array}{c}b-c \\
(b-c>a)\end{array}$ & $\begin{array}{c}\text { Significant Increase } \\
(19.8365 \rightarrow 33.5011)(\uparrow)\end{array}$ & $\begin{array}{c}\text { Moderate Decrease } \\
(19.8365 \rightarrow 14.9055)(\downarrow)\end{array}$ & $\begin{array}{c}0.4972 \text { (close to '0.5') } \\
\text { to } \\
0.8956 \text { (close to ' } 1 \text { ') }\end{array}$ & $\begin{array}{l}\text { Significant Decrease } \\
(19.8365 \rightarrow 6.6318)(\downarrow)\end{array}$ \\
\hline $\mathrm{b}$ & $\begin{array}{c}c-a \\
(c-a>b)\end{array}$ & $\begin{array}{l}\text { Significant Increase } \\
(19.8365 \rightarrow 33.5011)(\uparrow)\end{array}$ & $\begin{array}{c}\text { Moderate Decrease } \\
(19.8365 \rightarrow 14.9053)(\downarrow)\end{array}$ & $\begin{array}{c}0.4972 \text { (close to '0.5') } \\
\text { to } \\
0.8956 \text { (close to ' } 1 \text { ') }\end{array}$ & $\begin{array}{l}\text { Significant Decrease } \\
(19.8365 \rightarrow 6.6317)(\downarrow)\end{array}$ \\
\hline $\mathrm{c}$ & $\begin{array}{c}a-b \\
(a-b>c)\end{array}$ & $\begin{array}{l}\text { Significant Increase } \\
(19.8365 \rightarrow 33.4982)(\uparrow)\end{array}$ & $\begin{array}{c}\text { Moderate Decrease } \\
(19.8365 \rightarrow 14.9118)(\downarrow)\end{array}$ & $\begin{array}{c}0.4973 \text { (close to '0') } \\
\text { to } \\
0.8955 \text { (close to ' } 1 \text { ') }\end{array}$ & $\begin{array}{l}\text { Significant Decrease } \\
(19.8365 \rightarrow 6.6380)(\downarrow)\end{array}$ \\
\hline
\end{tabular}




\section{CONCLUSIONS}

In the present work, the computer simulation model is developed to simulate arbitrary variations in the state of degradation of stator groundwall insulation, occurring in respective phases of induction motor under test. An extended park's transformation model is used to transform the simulation results from three-phase ('abc') model into a more convenient and simplified form of equivalent two-phase (dq) model over a dq-plane. Extended park's current data patterns are derived from two-phase ('dq') model to distinguish the state of degradation of insulation. The performance analysis of electrical variables and extracted parameters of extended park's current data patterns for particular case is concluded here.

\subsection{Intermediate State of Degradation Present in Any One- Phase with Equal Variation from Healthy to Intermediate State of Degradation in Other Two-Phases}

An intermediate state of degradation of insulation present in any one particular phase is always more dominant as compared to the progressive increase in an equal state of degradation from healthy to intermediate state in other twophases. As detailed in 'Table 7,' the magnitude $\left(\mathrm{I}_{\mathrm{d}}, \mathrm{I}_{\mathrm{q}}\right.$, and $\left.\mathrm{I}_{\mathrm{dq}}\right)$ and phase-shift angle $\left(\beta_{\mathrm{d}}, \beta_{\mathrm{q}}\right.$, and $\left.\beta_{\mathrm{dq}}\right)$ of electrical variables in an equivalent two-phase (dq) model form responds in distinct manner for intermediate state of degradation of insulation present in any one particular phase (viz., a, b, and c) with progressive increase in an equal state of degradation from healthy to intermediate state in other two-phases (viz., b-c, c$a$, and $a-b)$, respectively.

In the forgoing discussion, the 'Table 8(a),' and Fig. 11 illustrates the change in the angle of orientation $\left(\theta_{0}^{\circ}\right)$ of an elliptic pattern (locus) over a dq-plane. It is imperative, that the variation in ' $\theta_{0}{ }^{\circ}$ ' is symmetrical and limited over a small range with respect to positive 'q-axis.' Similarly, the 'Table 8(a),' and Fig. 12 illustrates the change in the angle of majoraxis $\left(\theta_{\mathrm{m}}{ }^{\circ}\right)$ of an elliptic pattern over a dq-plane. It is imperative, that the variation in ' $\theta_{\mathrm{m}}{ }^{\circ}$ ' is symmetrically distributed by ' $120^{\circ}$ ' over distinct zones, in dq-plane. The corresponding simulation results in 'Table 8(a),' further suggests that these extracted parameters are sensitive within these specific limits in context of the progressive increase in an equal state of degradation of insulation (from healthy to intermediate state) in any two-phases (viz., b-c, c-a, and a-b) and a dominant intermediate state of degradation present in the remaining phase (viz., a, b, and c), respectively. As detailed in 'Table 8(b), the changes in the corresponding extracted parameters like ' $\mathrm{L}_{\mathrm{MA}}, \mathrm{L}_{\mathrm{MB}}, \mathrm{LR}$, and $\varepsilon$ ' are identical, irrespective of progressive increase in an equal state of degradation of insulation (from healthy to intermediate state) in any two-phases (viz., b-c, c-a, and a-b) and dominant intermediate state of degradation present in the remaining phase (viz., a, b, and c), respectively. The changes in an extracted parameters like ' $\mathrm{L}_{\mathrm{MA}}, \mathrm{L}_{\mathrm{MB}}$, and $\mathrm{LR}$ ' further suggests that the deformation in the shape of extended park's current elliptic pattern decreases with the change in an eccentricity $(\varepsilon)$ from ' 0.7939 ' viz., close to one (1) to ' 0.4688 ' viz., close to mid-value $(0.5)$.

\subsection{Intermediate State of Degradation Present in Any One-Phase with Equal Variation from Intermediate to Worst-case State of Degradation in Other Two-Phases}

An intermediate state of degradation of insulation present in any one particular phase is always less as compared to the progressive increase in an equal state of degradation from intermediate to worst-case state in other two-phases. As detailed in 'Table 9,' the magnitude $\left(\mathrm{I}_{\mathrm{d}}, \mathrm{I}_{\mathrm{q}}\right.$, and $\left.\mathrm{I}_{\mathrm{dq}}\right)$ and phaseshift angle $\left(\beta_{\mathrm{d}}, \beta_{\mathrm{q}}\right.$, and $\left.\beta_{\mathrm{dq}}\right)$ of electrical variables in the equivalent two-phase (dq) model form responds in distinct manner for intermediate state of degradation of insulation present in any one particular phase (viz., a, b, and c) with progressive increase in an equal state of degradation from intermediate to worst-case state in other two-phases (viz., b-c, $\mathrm{c}-\mathrm{a}$, and $\mathrm{a}-\mathrm{b})$, respectively.

In the forgoing discussion, the 'Table 10(a),' and Fig. 13 illustrates the change in the angle of orientation $\left(\theta_{0}^{\circ}\right)$ of an elliptic pattern (locus) over a dq-plane. It is imperative, that the variation in ' $\theta_{0}^{\circ}$ ' is symmetrical and limited over a small range with respect to positive 'q-axis.' Similarly, the 'Table 10(a),' and Fig. 14 illustrates the change in the angle of major-axis $\left(\theta_{\mathrm{m}}{ }^{\circ}\right)$ of an elliptic pattern over a dq-plane. It is imperative, that the variation in ' $\theta_{\mathrm{m}}{ }^{\circ}$ ' is symmetrically distributed by ' $120^{\circ}$ ' over distinct zones, in a dq-plane. The corresponding simulation results in 'Table 10(a), further suggests that these extracted parameters are sensitive within these specific limits in context of the progressive increase in a dominant equal state of degradation of insulation (from intermediate to worst-case state) in any two-phases (viz., b-c, $\mathrm{c}-\mathrm{a}$, and $\mathrm{a}-\mathrm{b})$ and an intermediate state of degradation present in the remaining phase (viz., a, b, and c), respectively. As detailed in 'Table 10(b),' the changes in the corresponding extracted parameters like ' $\mathrm{L}_{\mathrm{MA}}, \mathrm{L}_{\mathrm{MB}}$, $\mathrm{LR}$, and $\varepsilon$ ' are identical, irrespective of the progressive increase in a dominant equal state of degradation of insulation (from intermediate to worstcase state) in any two-phases (viz., b-c, c-a, and a-b) and an intermediate state of degradation present in the remaining phase (viz., a, b, and c), respectively. The changes in an extracted parameters like ' $\mathrm{L}_{\mathrm{MA}}, \mathrm{L}_{\mathrm{MB}}$, and $\mathrm{LR}$ ' further suggests that the deformation in the shape of extended park's current elliptic pattern increases with the change in an eccentricity $(\varepsilon)$ from ' 0.4972 ' viz., close to mid-value (0.5) to ' 0.8956 ' viz., close to one (1).

The extracted parameter like eccentricity $(\varepsilon)$ is not sufficient to decide the level of state of degradation of insulation. In fact, it only suggests the deformation in the shape of extended park's current elliptic pattern and in turn suggests the degree of unbalance in the three phase stator current. The extracted parameter like length of major-axis $\left(\mathrm{L}_{\mathrm{MA}}\right)$, length of minoraxis $\left(\mathrm{L}_{\mathrm{MB}}\right)$, and latus rectum (LR) suggests the size of extended park's current elliptic pattern and in turn are sensitive to decide level of state of degradation of insulation. Hence, extracted parameters like ' $\mathrm{L}_{\mathrm{MA}}, \mathrm{L}_{\mathrm{MB}}, \mathrm{LR}$, and $\varepsilon$ ' are useful to uniquely determine the qualitative level of variations (low, medium and high etc.) of an intermediate state of degradation of stator groundwall insulation present in any one particular phase and progressive increase in an equal state of degradation of insulation, occurring in other two-phases. 


\section{REFERENCES}

[1] H. Hirose, A method to estimate the lifetime of solid electrical insulation, IEEE Trans. Electrical Insulation. vol. 22 no. 6 (1987) 745-753.

[2] G. C. Montanari, M. Cacciari, Probabilistic Life Model for Insulating Materials Showing Electrical Thresholds, IEEE Trans. Electrical Insulation, vol. 24 (1989) 127134.

[3] Tsukui, T., M. Takamura, Y. Kako, Correlations between Nondestructive and Destructive Tests on High-Voltage Coil Insulations for Rotating Machines, IEEE Trans. Electrical Insulation. vol. 15 no. 2 (April 1980) 118-124.

[4] G. C. Stone, H. G. Sedding, B.A. Lloyd, B.K. Gupta, The ability of diagnostic tests to estimate the remaining life of stator insulation, IEEE Trans. Energy Conversion. vol. 3 no. 4 (Dec.1988) 833 - 841.

[5] A. J. Modak, H.P. Inamdar, Computer-Aided Characteristic Simulation Model of Deterioration of Insulation of Induction Motor, Proc. IEEE Press. Int. Conf., Computer and Electrical Engineering, UESTC, Chengdu, China. Nov. 16-18 (2010) VII-569-574, (ISBN: 978-1-4244-7224-6).

[6] N. Arthur, J. Penman, Induction machine conditioning monitoring with higher order spectra, IEEE Trans. Ind. Elect. vol. 47 no. 5 (Oct. 2000) 1031-1041.
[7] F. Filippetti, G. Franceschini, C. Tassoni , Peter Vas, Recent developments of induction motor drives fault diagnosis using AI techniques, IEEE Trans. Ind. Elect. vol. 47 no. 5 (Oct. 2000) $994-1004$

[8] C. Kral, R. S. Wieser, F. Pirker, M. Schagginger, Sequences of field oriented control for detection of faulty rotor bars in induction machines-The Vienna monitoring method, IEEE Trans. Ind. Elect., vol.47 no.5 (Oct.2000) 1042-1049.

[9] A. M. Trzynadlowski, E. Ritchie, Comparative investigation of diagnostic media for induction motor: A case of rotor cage faults, IEEE Trans. Ind. Elect. vol.47 no.5 (Oct. 2000) 1092-1099.

[10] F. C. Trutt et al., "Detection of AC machine winding deterioration using electrically excited vibrations," IEEE Trans. Ind. Applications. vol.17 no.1 (Jan. / Feb. 2001) $10-13$.

[11] A. J. M. Cardoso et al., Computer aided detection of air gap eccentricity in operating three phase induction motors by Park's vector approach, IEEE Trans. Ind. Applications. vol.29 (Sept. / Oct. 1993) 897-901.

[12] A. J. M. Cardoso et al., Inter turn stator winding fault diagnosis in three phase induction motors, by Park's vector approach, IEEE Trans. Energy Conversion. vol. 14 no. 3 (Sept.1999) 595-598. 